\title{
Effects of coating ingredients on the thermal properties and morphological structures of hydrocarbon intumescent coating chars
}

\author{
Zeng, Ying; Erik Weinell, Claus; Dam-Johansen, Kim; Ring, Louise ; Kiil, Søren
}

Published in:

Progress in Organic Coatings

Link to article, DOI:

10.1016/j.porgcoat.2020.105626

Publication date:

2020

Document Version

Peer reviewed version

Link back to DTU Orbit

Citation (APA):

Zeng, Y., Erik Weinell, C., Dam-Johansen, K., Ring, L., \& Kiil, S. (2020). Effects of coating ingredients on the thermal properties and morphological structures of hydrocarbon intumescent coating chars. Progress in Organic Coatings, 143, [105626]. https://doi.org/10.1016/j.porgcoat.2020.105626

\section{General rights}

Copyright and moral rights for the publications made accessible in the public portal are retained by the authors and/or other copyright owners and it is a condition of accessing publications that users recognise and abide by the legal requirements associated with these rights.

- Users may download and print one copy of any publication from the public portal for the purpose of private study or research.

- You may not further distribute the material or use it for any profit-making activity or commercial gain

- You may freely distribute the URL identifying the publication in the public portal 


\title{
Effects of coating ingredients on the thermal properties and morphological structures of hydrocarbon intumescent coating chars
}

\author{
Ying Zeng ${ }^{*}$, Claus Erik Weinell ${ }^{*}$, Kim Dam-Johansen*, Louise Ring ${ }^{\ddagger}$, Søren Kiil ${ }^{*}$, a \\ a: Corresponding author, email address: sk@kt.dtu.dk \\ *: Department of Chemical and Biochemical Engineering, Technical University of Denmark, DTU, Building 229, 2800 \\ Kgs. Lyngby, Denmark \\ *: Hempel A/S, Fire Protection-Group R\&D, Calle Can Vinyalets, 11, 08130 Santa Perpetua de Mogoda, Spain
}

\begin{abstract}
Mapping the performance of intumescent coatings as a function of concentration of ingredients is of great significance for formulation optimization. In this work, the effects of ammonium polyphosphate (APP), melamine (MEL), $\mathrm{TiO}_{2}, \mathrm{CaCO}_{3}$, and vitreous silicate fiber, were investigated on the fireresistance performance of selected zinc borate (ZB)-containing and ZB-free hydrocarbon intumescent coatings with exposure to the hydrocarbon fire testing curve UL 1709 . Owing to the promoted interactions of APP with epoxy binder and zinc borate, increasing levels of APP in the ZB-containing coatings enhanced the critical times of steel substrate and the formation of macroporous and compact char layers. In contrast, when increasing the content of MEL, the performance of the ZB-containing coatings generally declined, due mainly to the restricted char formation resulting from the decreased binder content. Among the investigated formulations, the coating with $25 \mathrm{wt} . \%$ APP or 5 wt.\% MEL obtained the best performance. The oxides $\mathrm{TiO}_{2}$ and $\mathrm{CaCO}_{3}$, and the fiber barely had effects on the performance of the ZB-containing intumescent coatings, but the critical times and char appearance were strongly affected for the ZB-free coatings. Increasing the content of any of the three inorganics led to reduced expansion of the ZB-free coatings, but improved the chars with more mechanically stable structures. The longest critical times (e.g. to $550^{\circ} \mathrm{C}$ ) were found with the ZB-free formulations containing 1.5 wt. $\% \mathrm{TiO}_{2}(87.7 \mathrm{~min}), 2.5 \mathrm{wt} . \% \mathrm{CaCO}_{3}(86.3 \mathrm{~min})$, and $5 \mathrm{wt} \%$ vitreous silicate fiber (85.1 $\mathrm{min})$.
\end{abstract}

Keywords: fire-resistance performance; critical times; char expansion. 


\section{Introduction}

Steel constructions, widely applied in modern architecture such as airports, oil rigs, and housing, are commonly specified to meet a given fire-resistance rating [1]. In general, this rating is determined by the time it takes the material to reach a certain critical temperature (often around $500{ }^{\circ} \mathrm{C}$ ) in a standard fire test [2]. Depending on the primary "fuel" of the anticipated fire, the test can be of the so-called cellulosic or hydrocarbon type, of which the latter has a much faster transient temperature rise than the former [3]. A practical way to accomplish the thermal insulation of steel structures is the application of intumescent coatings. Upon heat exposure, these coatings swell up to 100 times their original thickness, whereby a multicellular char with a low thermal conductivity is formed, which restricts the heat transfer from the hot gases of the fire to the underlying steel substrate. With the protection provided by intumescent coatings, the structural steel can attain a fire-resistance rating of 1-3 hours [4,5]. This greatly prolongs the time available for saving of lives and preservation of property.

Typically, intumescent coatings are composed of three fundamental ingredients: acid source, char former, and blowing agent. The acid source can be a mineral acid or a material which can generate acidic species upon heating. The char former, carbon-rich polyhydric compounds with numerous esterifiable sites (often hydroxyl groups), can cross-link with the acidic species through esterification reactions, thereby forming a mixture of esters. The intumescence of the mixture is accomplished by the release of incombustible gases from the blowing agent. The accurate coordination of acid generation, esterification, and gas release (as well as the viscosity reduction of the coating) is crucial to the working of an intumescent coating char [6,7]. Nevertheless, the chars formed with these three fundamental ingredients are generally vulnerable to the turbulent environments in fire scenarios. Therefore, to improve the fire-resistance properties (i.e. expansion, morphology, and thermal and mechanical stability) of the chars formed, diverse functional fillers, such as dolomite clay [8], titanium oxide [9-13], boric acid [14-16], kaolin [16-18], and montmorillonite [19-21], have all been added, in various concentrations, to intumescent coating formulations.

The studies of intumescent coatings were performed following either a temperature-time curve defined in the standard cellulosic fire test method with an adapted furnace [13], or non-standard curves using regular laboratory equipment, such as the Bunsen burner [8,9,12,14-18], the gas lamp [19], and/or the cone calorimeter [20]. However, none of the investigations comprehensively examined an epoxy-based intumescent coating system according to standard hydrocarbon fire test methods, such as the UL1709 or BS476 standards, where the gas temperature increases rapidly from room temperature to more than $900{ }^{\circ} \mathrm{C}$ within five minutes. 
The standard or standard-like test conditions can be crucial, especially for the intumescent coatings orientated towards hydrocarbon fire protection; quite a few studies have pointed out that the heating conditions directly affect the behavior of intumescent coatings in a complicated manner and thereby dramatically shape the fire-resistance properties of intumescent coating chars [22-29]. The present work is devoted to the study of the effects of five ingredients (ammonium polyphosphate, melamine, $\mathrm{TiO}_{2}, \mathrm{CaCO}_{3}$, and vitreous silicate fiber) on the fire-resistance performance of epoxy-based intumescent coatings, when exposed to the temperature-time curve defined by the standard hydrocarbon fire test method UL1709. Zinc borate, which is popularly formulated in hydrocarbon intumescent coatings owing to its efficiency in improving char structure, is expected to be replaced due to its health risks [30]. Therefore, two types of epoxy-based intumescent coating formulations (with and without zinc borate) were selected to represent the present commercial market and a potential boron-free future alternative.

\section{Experimental}

\subsection{Coating materials and application}

The epoxy-based hydrocarbon intumescent coatings studied were formulated with a two-component (base and curing part) system. The base part contained a bisphenol A epoxy resin (Hexion B.V.) and a diluent (ICL-IP B.V.), and filled with ammonium polyphosphate (100\% pure, Clariant GmbH), zinc borate ( $>98.8$ wt.\%, Borax Ltd.), calcium carbonate ( $>99$ wt.\%, Reverté Minerales S.A.), and vitreous silicate fiber (95-100 wt.\%, Rockwool B.V.; micrograph is shown in Figure 1). The curing part was composed of a polyamide (Air Products B.V.), a catalyst (Air Products B.V.), and filled with melamine (100 wt.\%, OCI Nitrogen B.V.) and titanium dioxide ( $>90$ wt.\%, Huntsman Ltd.). The distribution of the solid materials was chosen to balance pigment volume concentration in the two parts.

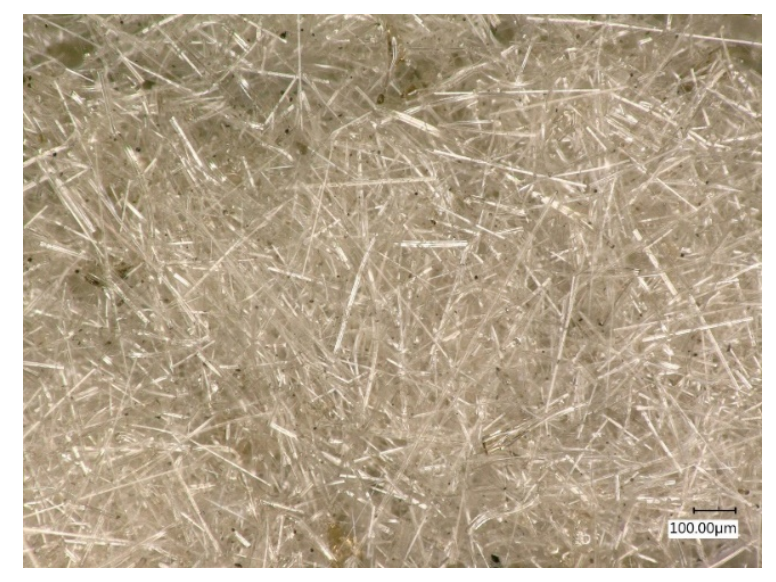

Figure 1 Micrograph of vitreous silicate fibers magnified 200 times with a digital microscope. 
The compositions of the intumescent coatings with and without zinc borate (ZB) are listed in Table 1 and Table 2, respectively. The components, ammonium polyphosphate (APP), melamine (MEL), titanium dioxide $\left(\mathrm{TiO}_{2}\right)$, calcium carbonate $\left(\mathrm{CaCO}_{3}\right)$, and vitreous silicate fiber, were investigated individually in the hydrocarbon intumescent coating system. For a target component (e.g. $\left.\mathrm{TiO}_{2}\right)$, its mass fraction was adjusted by varying the epoxy binder content accordingly, and the levels of all other components were constant. This was thought to be a sound way of studying and comparing the effects of these components, because the effects of the epoxy binder system, which have previously been thoroughly investigated in the literature [3,31-34], are supposed to be distinguished readily to identify the effects of the target component. The pigment volume concentrations (PVC) and critical pigment volume concentrations (CPVC) of the coatings, calculated with equations described elsewhere [35], are given in Table 1 and Table 2. Melamine does not dissolve in the liquid binder and was included in the particulate phase with the other powdery materials.

Dispersion of the base and curing part was done with a high-speed disperser at $1600 \mathrm{rpm}$ (decreased to $400 \mathrm{rpm}$ when vitreous silicate fiber was added to avoid breakage). To avoid accidents, mixing and dispersion were conducted below $50{ }^{\circ} \mathrm{C}$, a temperature substantially lower than the flash point of all liquid ingredients (the lowest flash point was $140^{\circ} \mathrm{C}$ ). The intumescent coatings were prepared by mixing the well-dispersed base and curing part according to an amide/epoxy functional group stoichiometric ratio of 0.867 . For a fire-resistance experiment, the coating was applied to the surface of a grit-blasted steel plate (area of $60 \times 60 \mathrm{~mm}^{2}$ and $3 \mathrm{~mm}$ thickness) in a film thickness of $6 \pm 0.2$ $\mathrm{mm}$ using first a spatula and then a roller. All samples were cured for 24 hours at room temperature before use. Figure 2 shows the example of a steel plate coated with a cured intumescent coating sample.

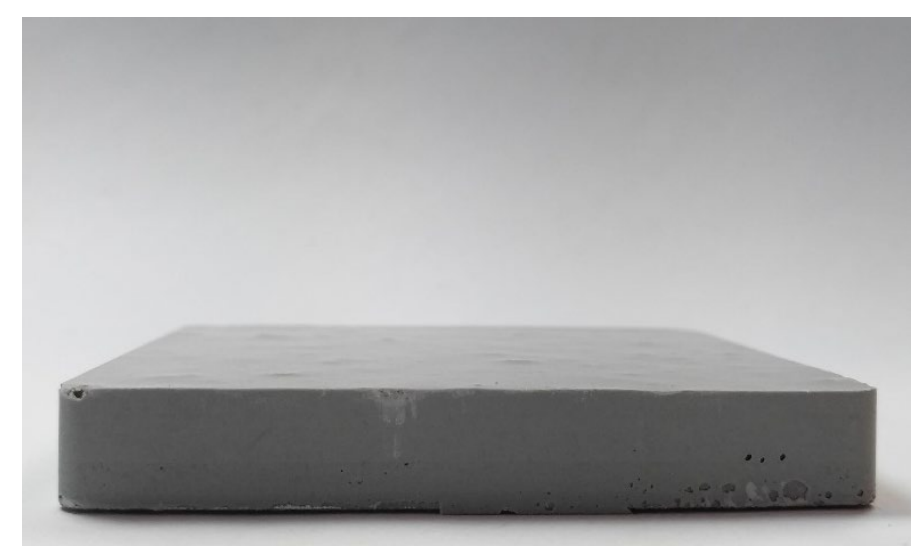

Figure 2 An intumescent coating sample applied on a grit-blasted steel plate. 
Table 1 Composition of the series of zinc borate intumescent coatings (in wt.\%), APP = ammonium polyphosphate, $\mathrm{MEL}=$ melamine, $\mathrm{ZB}=$ zinc borate.

\begin{tabular}{lccccccccc}
\hline $\begin{array}{l}\text { Coating } \\
\text { name }\end{array}$ & APP & MEL & $\mathrm{ZB}$ & $\mathrm{TiO}_{2}$ & $\mathrm{CaCO}_{3}$ & $\begin{array}{c}\text { Vitreous } \\
\text { silicate fiber }\end{array}$ & $\begin{array}{c}\text { Binder } \\
\text { system }\end{array}$ & $\begin{array}{c}\text { PVC } \\
(\%)\end{array}$ & $\begin{array}{c}\mathrm{CPVC} \\
(\%)\end{array}$ \\
\hline APP & & & & & & & & & \\
ZB-A10 & 10.00 & 12.63 & 5.00 & 3.44 & 1.44 & 10.18 & 57.31 & 28.31 & 35.99 \\
ZB-A15 & 15.00 & 12.63 & 5.00 & 3.44 & 1.44 & 10.18 & 52.31 & 32.82 & 38.05 \\
ZB-A20 & 20.00 & 12.63 & 5.00 & 3.44 & 1.44 & 10.18 & 47.31 & 37.58 & 39.85 \\
ZB-A25 & 25.00 & 12.63 & 5.00 & 3.44 & 1.44 & 10.18 & 42.31 & 42.61 & 41.46 \\
\hline MEL & & & & & & & & & \\
ZB-M5 & 15.79 & 5.00 & 5.00 & 3.44 & 1.44 & 10.18 & 59.15 & 25.84 & 34.26 \\
ZB-M10 & 15.79 & 10.00 & 5.00 & 3.44 & 1.44 & 10.18 & 54.15 & 30.85 & 37.05 \\
ZB-M15 & 15.79 & 15.00 & 5.00 & 3.44 & 1.44 & 10.18 & 49.15 & 36.04 & 39.44 \\
\hline TiO2 & & & & & & & & & \\
ZB-T2 & 15.79 & 12.63 & 5.00 & 2.00 & 1.44 & 10.18 & 52.95 & 32.61 & 38.18 \\
ZB-T6 & 15.79 & 12.63 & 5.00 & 6.00 & 1.44 & 10.18 & 48.95 & 35.31 & 38.64 \\
ZB-T10 & 15.79 & 12.63 & 5.00 & 10.00 & 1.44 & 10.18 & 44.95 & 38.23 & 39.06 \\
\hline CaCO3 & & & & & & & & & \\
ZB-C0.5 & 15.79 & 12.63 & 5.00 & 3.44 & 0.50 & 10.18 & 52.45 & 32.82 & 38.10 \\
ZB-C5 & 15.79 & 12.63 & 5.00 & 3.44 & 5.00 & 10.18 & 47.95 & 36.43 & 39.24 \\
ZB-C10 & 15.79 & 12.63 & 5.00 & 3.44 & 10.00 & 10.18 & 42.95 & 40.75 & 40.41 \\
\hline Vitreous silicate fiber & & & & & & & \\
ZB-F6 & 15.79 & 12.63 & 5.00 & 3.44 & 1.44 & 6.00 & 55.69 & 30.40 & 45.48 \\
ZB-F10 & 15.79 & 12.63 & 5.00 & 3.44 & 1.44 & 10.00 & 51.69 & 33.41 & 38.60 \\
ZB-F14 & 15.79 & 12.63 & 5.00 & 3.44 & 1.44 & 14.00 & 47.69 & 36.62 & 34.05 \\
\hline Corespon & 15.79 & 12.63 & 5.00 & 3.44 & 1.44 & 18.00 & 43.69 & 40.04 & 30.82 \\
\hline
\end{tabular}

${ }^{a}$ Corresponding to the total amount of the epoxy resin, diluent, amide, and catalyst. The ratio between these components was kept constant in all the formulations. 
Table 2 Composition of the series of zinc borate-free intumescent coatings (in wt.\%), APP = ammonium polyphosphate, $\mathrm{MEL}=$ melamine.

\begin{tabular}{|c|c|c|c|c|c|c|c|c|}
\hline $\begin{array}{l}\text { Coating } \\
\text { name }\end{array}$ & APP & MEL & $\mathrm{TiO}_{2}$ & $\mathrm{CaCO}_{3}$ & $\begin{array}{l}\text { Vitreous } \\
\text { silicate fiber }\end{array}$ & $\begin{array}{l}\text { Binder } \\
\text { system }^{\text {a }}\end{array}$ & $\begin{array}{l}\text { PVC } \\
(\%)\end{array}$ & $\begin{array}{c}\text { CPVC } \\
(\%)\end{array}$ \\
\hline \multicolumn{9}{|l|}{$\mathrm{TiO}_{2}$} \\
\hline T0 & 15.79 & 12.63 & 0.00 & 1.44 & 10.18 & 59.96 & 27.66 & 36.30 \\
\hline $\mathrm{T} 1.5$ & 15.79 & 12.63 & 1.50 & 1.44 & 10.18 & 58.46 & 28.53 & 36.50 \\
\hline T5 & 15.79 & 12.63 & 5.00 & 1.44 & 10.18 & 54.96 & 30.66 & 36.97 \\
\hline $\mathrm{T} 10$ & 15.79 & 12.63 & 15.00 & 1.44 & 10.18 & 49.96 & 33.94 & 37.59 \\
\hline $\mathrm{T} 15$ & 15.79 & 12.63 & 20.00 & 1.44 & 10.18 & 44.96 & 37.56 & 38.16 \\
\hline \multicolumn{9}{|l|}{$\mathrm{CaCO}_{3}$} \\
\hline $\mathrm{C} 0$ & 15.79 & 12.63 & 3.44 & 0.00 & 10.18 & 57.96 & 28.65 & 36.34 \\
\hline $\mathrm{C} 2.5$ & 15.79 & 12.63 & 3.44 & 2.50 & 10.18 & 55.46 & 30.47 & 37.06 \\
\hline $\mathrm{C} 5$ & 15.79 & 12.63 & 3.44 & 5.00 & 10.18 & 52.96 & 32.36 & 37.75 \\
\hline $\mathrm{C} 10$ & 15.79 & 12.63 & 3.44 & 10.00 & 10.18 & 47.96 & 36.36 & 39.03 \\
\hline C15 & 15.79 & 12.63 & 3.44 & 15.00 & 10.18 & 42.96 & 40.68 & 40.20 \\
\hline \multicolumn{9}{|c|}{ Vitreous silicate fiber } \\
\hline F0 & 15.79 & 12.63 & 3.44 & 1.44 & 0.00 & 66.70 & 22.84 & 65.88 \\
\hline F5 & 15.79 & 12.63 & 3.44 & 1.44 & 5.00 & 61.70 & 26.08 & 46.18 \\
\hline F10 & 15.79 & 12.63 & 3.44 & 1.44 & 10.00 & 56.70 & 29.56 & 37.00 \\
\hline F15 & 15.79 & 12.63 & 3.44 & 1.44 & 15.00 & 51.70 & 33.31 & 31.69 \\
\hline F20 & 15.79 & 12.63 & 3.44 & 1.44 & 20.00 & 46.70 & 37.35 & 28.23 \\
\hline
\end{tabular}

${ }^{\mathrm{a}}$ Corresponding to the total amount of the epoxy resin, diluent, amide, and catalyst. The ratio between these components was kept constant in all the formulations.

\subsubsection{Fire-resistance experiments following the UL1709 curve}

Fire-resistance experiments of the intumescent coatings were carried out with a compact furnace modified with an opening in the furnace door for sample placement (details are available elsewhere [28]). A steel plate coated with an intumescent coating was mounted vertically with a tailor-cut insulation material (VIP12-HT supplied by Skamol A/S, thickness of $50 \mathrm{~mm}$ ) between the plate backside and the accessories that immobilize the sample. The temperature response of the steel plate during the fire-resistance experiment was recorded with a copper-disk thermocouple (K-type, $0-700$ ${ }^{\circ} \mathrm{C}$ ) attached to the central area of the backside of the steel plate. The thermocouple was connected to a data logger that recorded temperature with a time interval of $1 \mathrm{~s}$. 
The fire-resistance experiments were initiated by heating the furnace chamber according to the temperature-time relationship stated in the standard hydrocarbon fire test method UL1709. Once the temperature of the steel plate reached a critical value of $550{ }^{\circ} \mathrm{C}$, the furnace was turned off. The value of $550{ }^{\circ} \mathrm{C}$ was selected because it covers both the standard critical temperature of $400{ }^{\circ} \mathrm{C}$ for heavily loaded structural steel components, and the standard of $550{ }^{\circ} \mathrm{C}$ for normally loaded components such as onshore platforms. The intumescent chars formed in the fire-resistance experiments were taken out for further analyses when the furnace had cooled down to room temperature. Key parameters of the fire-resistance experiment are the times that the steel plate takes to reach the critical temperatures of 400 and $550{ }^{\circ} \mathrm{C}$ (i.e. the critical times) as well as characterizations of the chars formed. For each of the intumescent coatings, a repetition of the fire-resistance experiments was performed and the average of the results (including the temperature response and the critical times of the steel plate) was used in the subsequent analysis.

\subsubsection{Digital microscope recordings of intumescent char structures}

A digital microscope (VHX-6000, from KEYENCE) with a VH-Z20T lens was used to observe the structures of the intumescent coating chars formed in the fire-resistance experiments.

\section{Results and discussion}

\subsection{Zinc Borate (ZB)-containing intumescent coatings}

The effects of the five components, APP, $\mathrm{MEL}, \mathrm{TiO}_{2}, \mathrm{CaCO}_{3}$, and vitreous silicate fiber, on the fireresistance performance of the intumescent coatings were studied in the systems with zinc borate. The results are presented in the following sections. The performance parameters including the temperature-time response and critical times of the coated steel plate, relative expansion and morphological structure of intumescent char are addressed.

\subsubsection{Fire-resistance performance}

The effects of the five components on the performance of ZB-containing intumescent coatings were first examined. Figure 3 shows the temperature-time responses of the steel plates obtained from the fire-resistance experiments. The curves are the average of the two repetition experiments and the standard deviation of the data points are in all cases within 4 min (not shown in the figure). Both the levels of APP and MEL exhibited certain influences on the fire-resistance performance of the ZBcontaining intumescent coatings, while the cases of the inorganic components $\left(\mathrm{TiO}_{2}, \mathrm{CaCO}_{3}\right.$, and vitreous silicate fiber) showed almost the same temperature progression, regardless of the levels and species of the target component. 

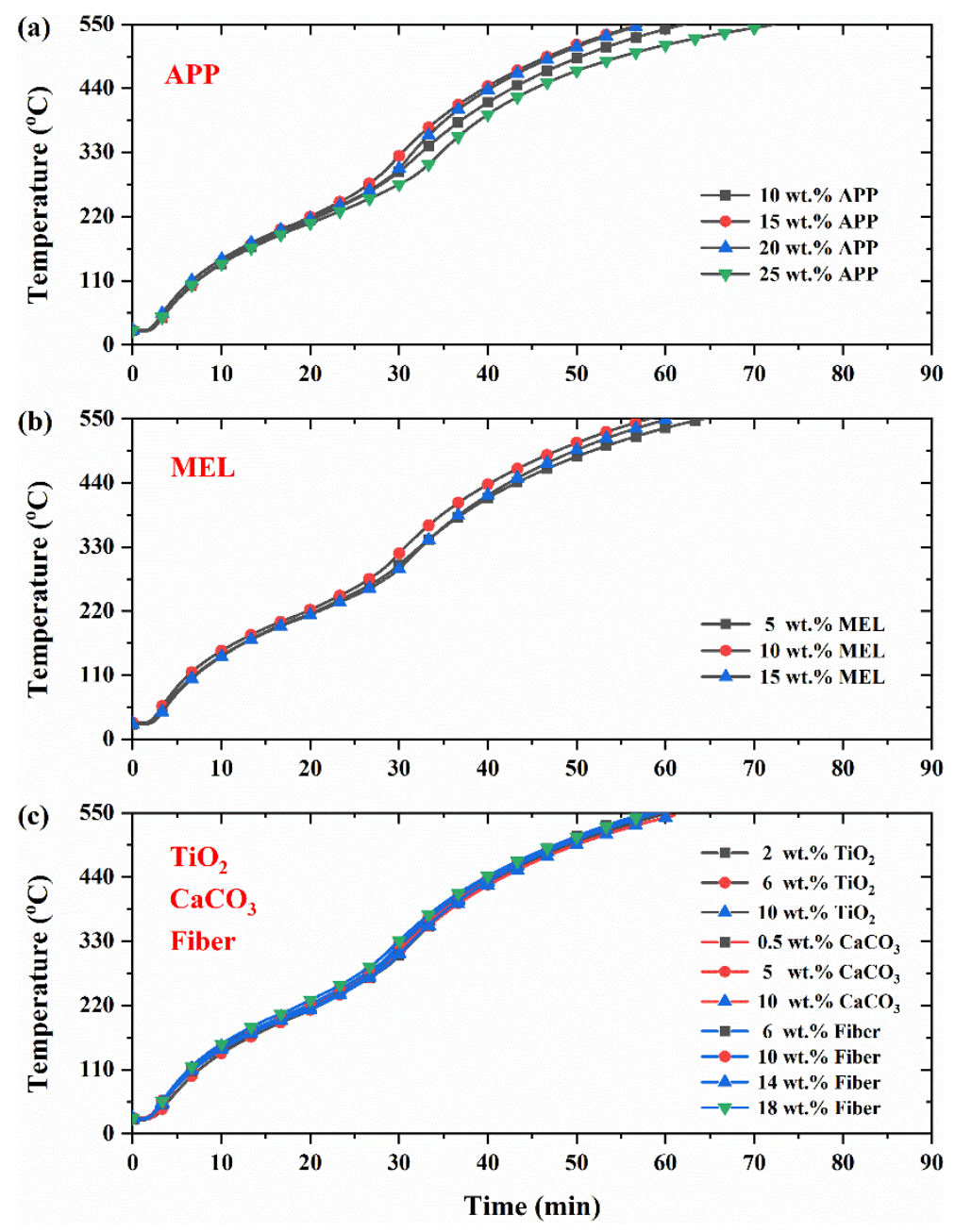

Figure 3 Temperature versus time curves of the steel plates coated with ZB-containing intumescent coatings in the fire-resistance experiments. The coatings differ in the concentration levels of APP, $\mathrm{MEL}, \mathrm{TiO}_{2}, \mathrm{CaCO}_{3}$, and vitreous silicate fiber.

Figure 4 summarizes the critical times of the coated steel plates to reach the critical temperatures (400 and $550{ }^{\circ} \mathrm{C}$ ). The critical times are averages ( \pm standard deviation) of the repetition experiments. The most distinct change was displayed by increasing the mass fraction of APP for which the critical time was decreased first and then increased. The longest critical time to 400 and $550{ }^{\circ} \mathrm{C}$ was 40.5 and 73.0 min with the coating containing $25 \mathrm{wt} . \%$ APP. Similar variation in the critical times was observed when raising the level of MEL, although the changes were lessened and the best performance (38.5 and $64.3 \mathrm{~min}$ to 400 and $550{ }^{\circ} \mathrm{C}$ ) was found with the coating comprising the lowest content of MEL (i.e. 5 wt.\%). Regarding the inorganic components $\left(\mathrm{TiO}_{2}, \mathrm{CaCO}_{3}\right.$, and vitreous silicate fiber), the critical times of the samples to 400 and $550{ }^{\circ} \mathrm{C}$ varied quite marginally from 35.5 to 37.8 min and from 57.7 to $62.1 \mathrm{~min}$. 


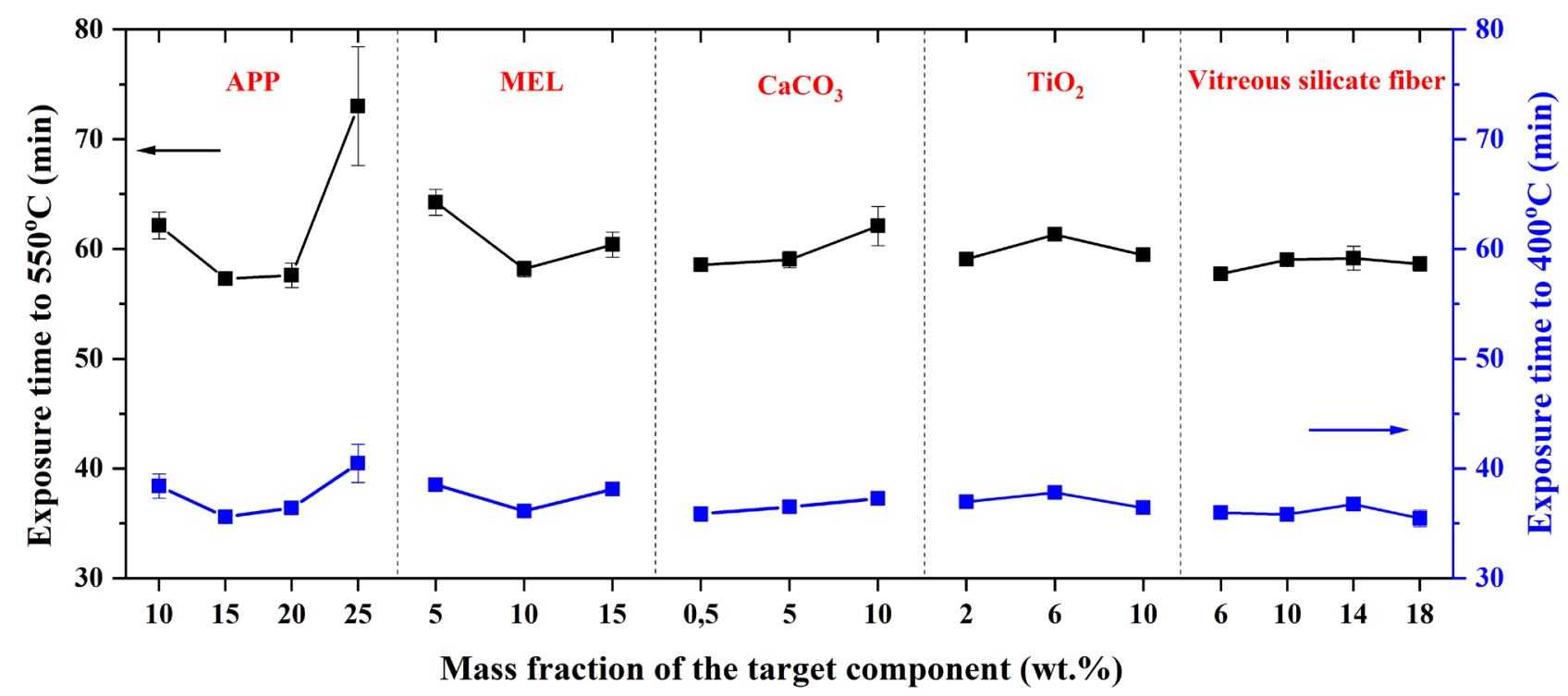

Figure 4 Average critical times of the ZB-containing intumescent coatings. Error bars correspond to the standard deviation.

The results show that increasing the content of APP or decreasing the content of MEL generally improved the fire-resistance performance of the ZB-containing coatings (aside from the anomalous value), while adjusting the levels of the inorganics, $\mathrm{TiO}_{2}, \mathrm{CaCO}_{3}$, and the fiber, barely presented notable effect. The performance of these inorganics is quite surprising, as it is in contradiction to results found in the literature. For example, Ahmad's group from Malaysia has claimed that the content of $\mathrm{TiO}_{2}$ has an active role in extending thermal protection time of intumescent systems with zinc borate and/or boric acid $[9,11,12]$. A possible explanation for the divergence is the different intumescent formulations and heating conditions of fire-resistance experiments applied in the present work and the literature reports. Due to the possible interactions among the different ingredients being very complex, the influence of the actual formulations cannot be mapped here. However, with regard to the heating conditions, as discussed in the introduction part, these are certainly expected to have an effect on the fire-resistance performance of the intumescent coatings. Compared with the present work, the fire-resistance experiments in the relevant literature were performed under a more moderate temperature environment (e.g. fire protection tests with a Bunsen burner in Ahmad's group), where the temperature progressions of the steel plates were sluggish and nearly flattened at temperatures below $300{ }^{\circ} \mathrm{C}[9,11,12]$. In such cases, more substances, e.g. polyphosphoric acid that derives from ammonium polyphosphate and dehydrates to sublimate at around $550{ }^{\circ} \mathrm{C}[36]$, may be retained longer and can react with oxides such as $\mathrm{TiO}_{2}$, increasing the probability of additional interactions. 


\subsubsection{Physical appearance of the intumescent chars}

The effects of the five components on the expansion ratios of the coatings and the morphological structures of the chars were examined. Figure 5 shows the relative expansion of the ZB-containing intumescent coatings, which were estimated by dividing the average height of the chars formed in the repetition of fire-resistance experiments with the original dry film thickness of the coating. By increasing the level of APP, the relative expansion of the chars were first abruptly reduced to its minimum and then gradually increased. The highest relative expansion was found with the coating containing $10 \mathrm{wt} . \%$ APP (ZB-A10). In the case of MEL, the increased mass fraction resulted in a steadily decreasing char expansion. $\mathrm{TiO}_{2}, \mathrm{CaCO}_{3}$, and the fiber exhibited a limited influence on the expansion of the ZB-containing intumescent coatings, coinciding with their performance in the temperature responses and critical times in Figure 3 and Figure 4. The changes caused by adjusting these inorganics components are at the same level as the standard deviations of the experiments.

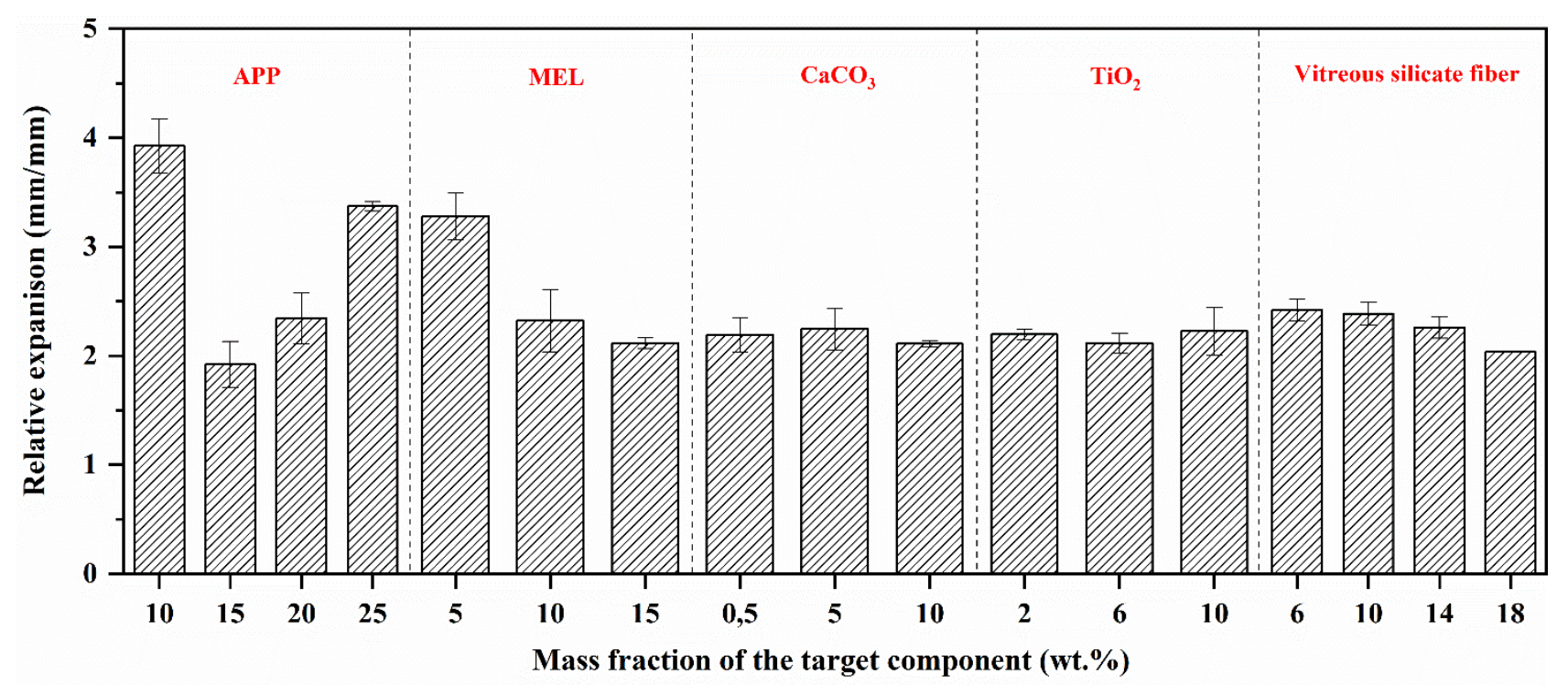

Figure 5 Char expansions, relative to the initial coating thickness, as a function of the content of the target component in the ZB-containing intumescent coatings. Error bars represent the standard deviation.

The cross-sectional structures of the intumescent chars were recorded with a digital microscope using 20 times magnification. Figure 6 shows the results obtained with the varied APP levels. All the chars present a two-layered structure: a foam-like macroporous structure with a grey color appears on top, while the black compact layer is placed at the bottom. By increasing the content of APP from 10 to 25 wt.\%, the void (cell) size and thickness of the macroporous structure dropped and gradually increased. In contrast, the depth of the compact phase was consistently enlarged from 3.5 to $6.7 \mathrm{~mm}$ by formulating with more APP in the coatings. Comparing with the relative expansion shown in 
Figure 5, it can be seen that the highest relative expansion of the coating ZB-A10 (10 wt.\% APP) resulted from its great depth of the macroporous structure, while the increased char expansion from the coating with 15 to 25 wt.\% APP benefited from both the increased macroporous and compact phase. In general, except for the macroporous layer observed in the case of ZB-A10, the high levels of APP apparently presented positive effects on the foam of the macroporous structure and the formation of the compact phase.
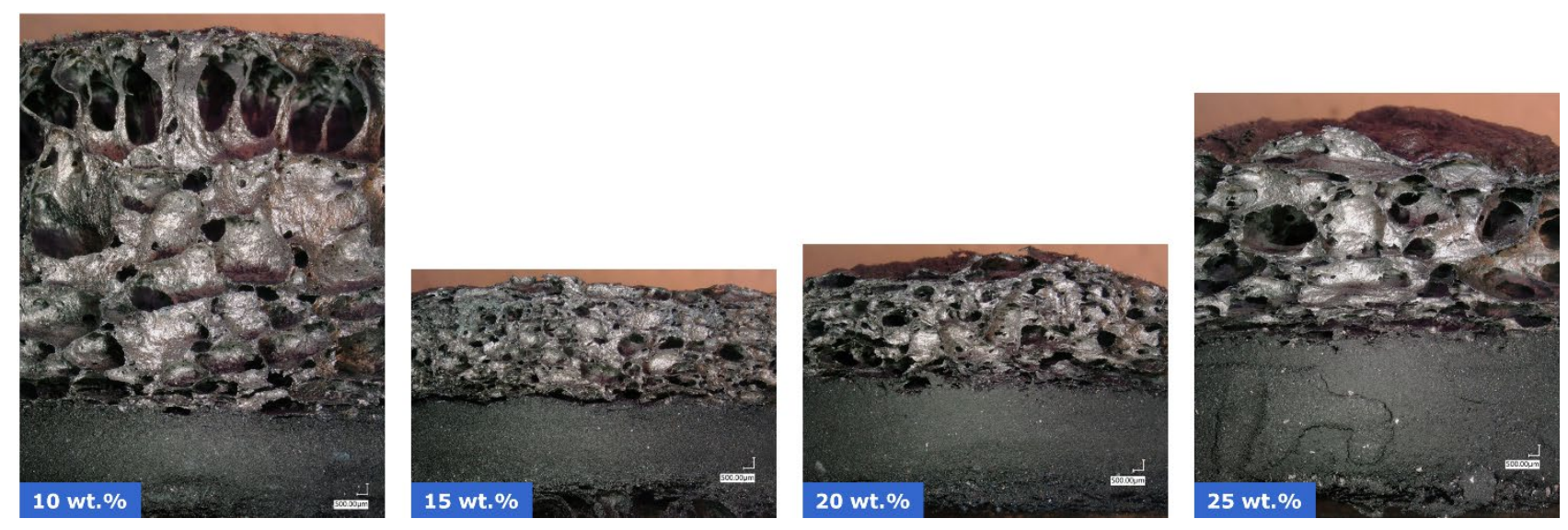

Figure 6 Cross-sections of the chars formed with ZB-containing intumescent coatings containing different levels of APP. The images were recorded with a digital microscope magnified 20 times.

The well-expanded macroporous layer formed with the coating ZB-A10 certainly explains its good fire-resistance performance (i.e. long critical times of the steel plates) in the furnace experiments, although the reason for forming this structure is not yet clear. Nevertheless, aside from this exception, the positive effects of APP on the char appearance may be on account of its reactions in the system. With the present ZB-containing intumescent formulations, the main reactions of APP, occurring at similar temperatures, are releasing ammonia $\left(\mathrm{T}>250{ }^{\circ} \mathrm{C}[30]\right)$ to promote char expansion, and its derivative polyphosphoric acid reacting with the cured epoxy $\left(\mathrm{T}<280{ }^{\circ} \mathrm{C}[7]\right)$ and zinc borate $\left(\mathrm{T} \geq 300^{\circ} \mathrm{C}[36]\right)$. The stoichiometry molar ratio of the latter two reactions are APP (repeating unit): cured epoxy (hydroxyl group): zinc borate $=1: 0.5: 0.05$ [36,37]. Facilitating these reactions (e.g. via increasing concentration of reactant APP unless a substantial stoichiometric excess is reached) improves the char structure, thermal stability of the coating, and the residual weight of the char $[3,34,38]$. However, in the present system, even with the coating ZB-A25, which has the highest content of APP and the lowest content of the epoxy binder, the molar ratio of APP to the hydroxyl group of the cured epoxy, and zinc borate is merely 1: 0.49: 0.05. It is just theoretically enough for the main reactions of APP and far less than a level of stoichiometric excess. Therefore, it seems reasonable that increasing the content of APP improves the char expansion (contribution from both 
the macroporous and the compact phase) and consequently the fire-resistance performance of the coatings.

The variation of the char structures caused by the different levels of MEL is illustrated in Figure 7. By enhancing the content of MEL from 5 to $15 \mathrm{wt} . \%$, the char layer including the macroporous and compact phase became denser. Coinciding with the trend observed in the relative expansion, the thickness of the compact phase was reduced from 6.9 to $5.8 \mathrm{~mm}$. These results are quite surprising, as the increase of the MEL level was expected to yield more ammonia to benefit char expansion.
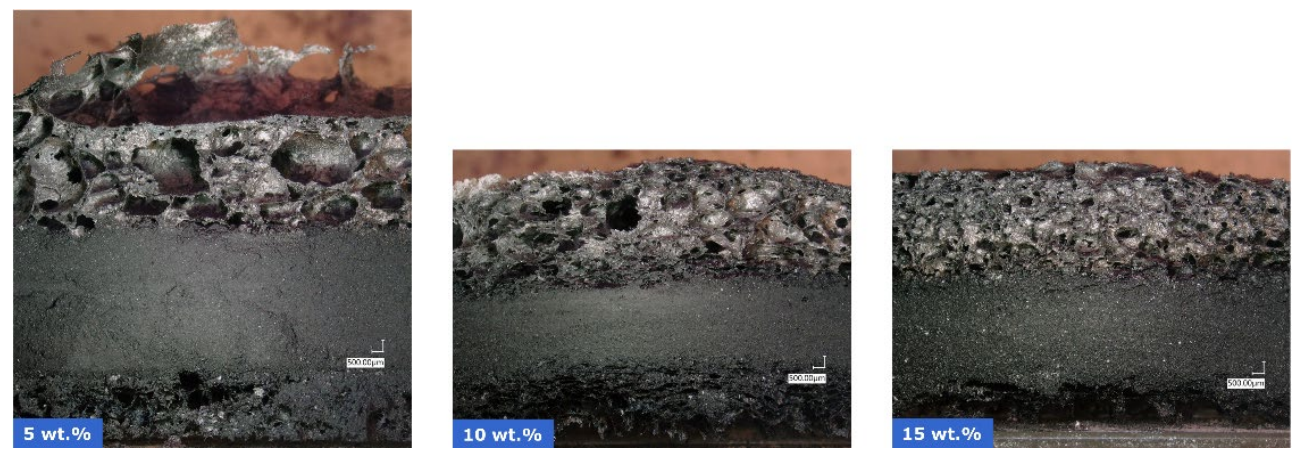

Figure 7 Cross-sections of the chars formed with ZB-containing intumescent coatings containing different levels of MEL. The images were recorded with a digital microscope magnified 20 times.

This shows that it is important to ensure that a well-expanded char does not only rely on the amount of gases released from blowing agents, but also the amount of substances in the incipient char for foaming and the viscosity of the incipient char for trapping the gases [7,29,30,39]. By increasing the level of MEL, the content of the epoxy binder, which contributes to the yield of the incipient char, was decreased accordingly; the viscosity of the melted incipient char may increase due to the introduction of more solid particles (i.e. MEL) and thus generate higher internal stress for char stretching $[39,40]$. Moreover, the cured epoxy binder could serve as a blowing agent to some extent, as it decomposes plenty of gases such as $\mathrm{CO}_{2}, \mathrm{H}_{2} \mathrm{O}$, and low-molecular volatiles during thermal degradation [30,41]. Therefore, the increment of gas release due to the increased level of MEL may partly be offset by the reduction of the binder content. In summary, all these factors could be responsible for the reduced char expansion (including the thickness of the macroporous and compact phase) and inferior fire-resistance performance observed with the coatings containing the high level of MEL. However, a lower char expansion does not necessarily result in a poorer fire-resistance performance (especially when the variation of char expansion is within a narrow range), because a compact char structure could possess better insulation properties [30]. This may explain the results that the coating ZB-M15 with the lowest expansion and densest structure did not exhibit the worst fire-resistance performance. Furthermore, it has to be noted that the negative effects of decreasing 
binder content was not shown in the case of APP due mainly to that APP functions not only as a blowing agent like MEL does, but more decisively as an acid source that generally promotes the coating performance via interactions with other ingredients (see the earlier discussion).

With regard to the cases of $\mathrm{TiO}_{2}, \mathrm{CaCO}_{3}$, and vitreous silicate fiber, their influences on the morphological structures of the chars are quite similar to each other (see Figure 8). By increasing the mass fraction of these inorganic components, the most observable change was the gradually reduced voids (cells) size in the macroporous structure. The slightly varied structures may also relate to the decreased binder content. However, in contrast to the case of MEL, the amount of substances in the incipient chars would increase by raising the contents of these non-volatile compounds. This probably accounts for the fact that the char expansion was not evidently changed in the results of these inorganics.

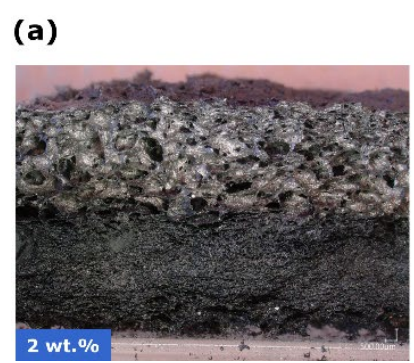

(b)

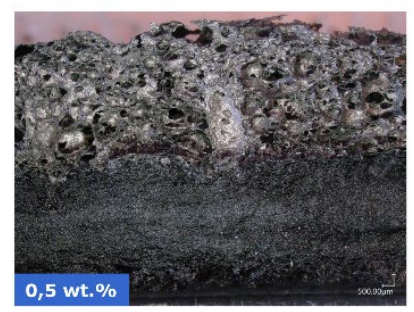

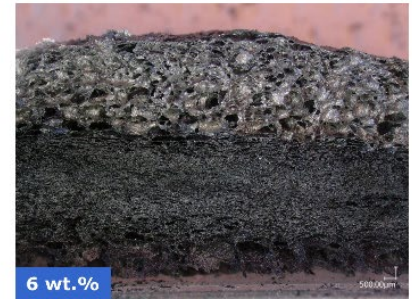

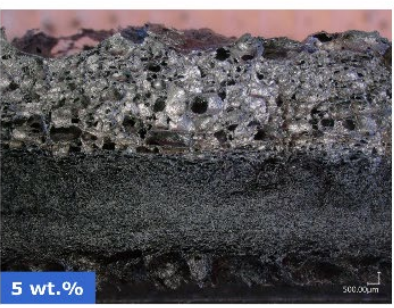

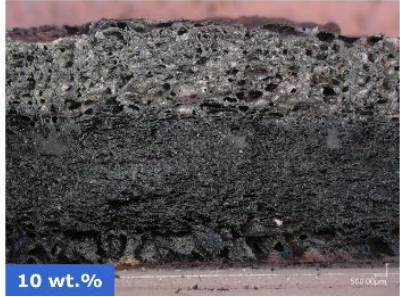

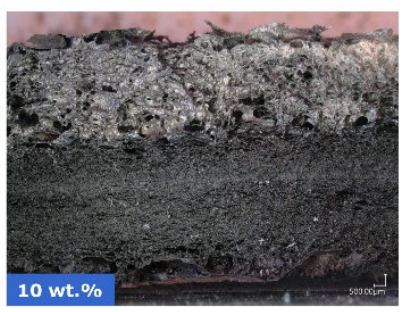

(c)
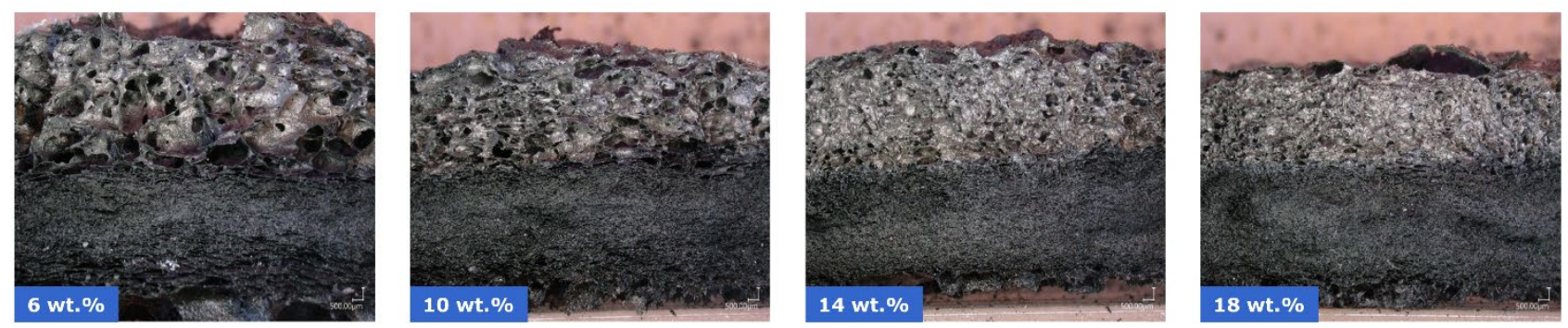

Figure 8 Cross-sections of the chars formed with ZB-containing intumescent coatings containing different levels of (a) $\mathrm{TiO}_{2}$, (b) $\mathrm{CaCO}_{3}$, and (c) vitreous silicate fiber. The images were recorded with a digital microscope magnified 20 times.

Nevertheless, these types of inorganics are usually expected to affect the performance of an intumescent coating via their interactions with other active compounds in the formulation, e.g. $\mathrm{TiO}_{2}$ 
reacting with APP, instead of simply their influences on binder content. As shown in Figure 8, some differences do exist between the effects of these three components. Specifically, the binder contents in the coatings with $2 \mathrm{wt} . \% \mathrm{TiO}_{2}, 0.5 \mathrm{wt} . \% \mathrm{CaCO}_{3}$, and $10 \mathrm{wt} . \%$ fiber are almost the same. When the approximately equal amount of the binder was decreased (i.e. from 2 to 6 wt.\% $\mathrm{TiO}_{2}, 0.5$ to 5 wt.\% $\mathrm{CaCO}_{3}$, and 10 to 14 wt.\% fiber), the extent to which the macroporous structure was affected is clearly different and depends on the type of the compound. Adjusting the level of the fiber demonstrated more distinct change on the size of the voids compared with the cases of $\mathrm{TiO}_{2}$ and $\mathrm{CaCO}_{3}$. Nonetheless, compared to our previous work on zinc borate which can distinctly impact the performance of the intumescent coatings (including the fire-resistance performance and char structures) [30], the effects exhibited by $\mathrm{TiO}_{2}, \mathrm{CaCO}_{3}$, and the fiber are quite limited. Their insignificant effects on the physical appearance of the intumescent chars explain the similar temperature responses of the coated steel plates shown in Figure 3.

The restricted performance of $\mathrm{TiO}_{2}, \mathrm{CaCO}_{3}$, and the fiber is probably due to the presence of zinc borate, which actively reacts with APP and its derivatives with a strong influence on the viscosity of incipient chars $[30,36]$. The room for these three inorganics to show an effect may be small in the ZB-containing formulations. Therefore, from the perspective of formulation design, low contents of $\mathrm{TiO}_{2}, \mathrm{CaCO}_{3}$, and the fiber (only valid for the investigated ranges) could be used to permit a high level of other compounds that can effectively improve the performance of the ZB-containing intumescent coatings (e.g. APP, zinc borate).

\subsection{Zinc borate (ZB)-free intumescent coatings}

Due to the suspected toxicity of boron compounds, investigation of the behavior of ZB-free coatings is in line with the ongoing search for boron-free hydrocarbon intumescent formulations. With the studies of the ZB-containing intumescent coatings, it is plausible to assume that APP and MEL would take similar effects in $\mathrm{ZB}$-free coatings, while $\mathrm{TiO}_{2}, \mathrm{CaCO}_{3}$, and vitreous silicate fiber may perform differently in the absence of zinc borate. Consequently, the effects of $\mathrm{TiO}_{2}, \mathrm{CaCO}_{3}$, and the fiber on the ZB-free intumescent coatings were studied and the results are presented in this section.

\subsubsection{Fire-resistance performance}

Figure 9 shows the average temperature-time response of the steel plate coated with a ZB-free intumescent coating in the repetitive fire-resistance experiments. Unlike the results observed with the ZB-containing intumescent coatings, the levels of $\mathrm{TiO}_{2}, \mathrm{CaCO}_{3}$, and vitreous silicate fiber in the ZBfree systems actively influence the temperature response of the steel plates. 

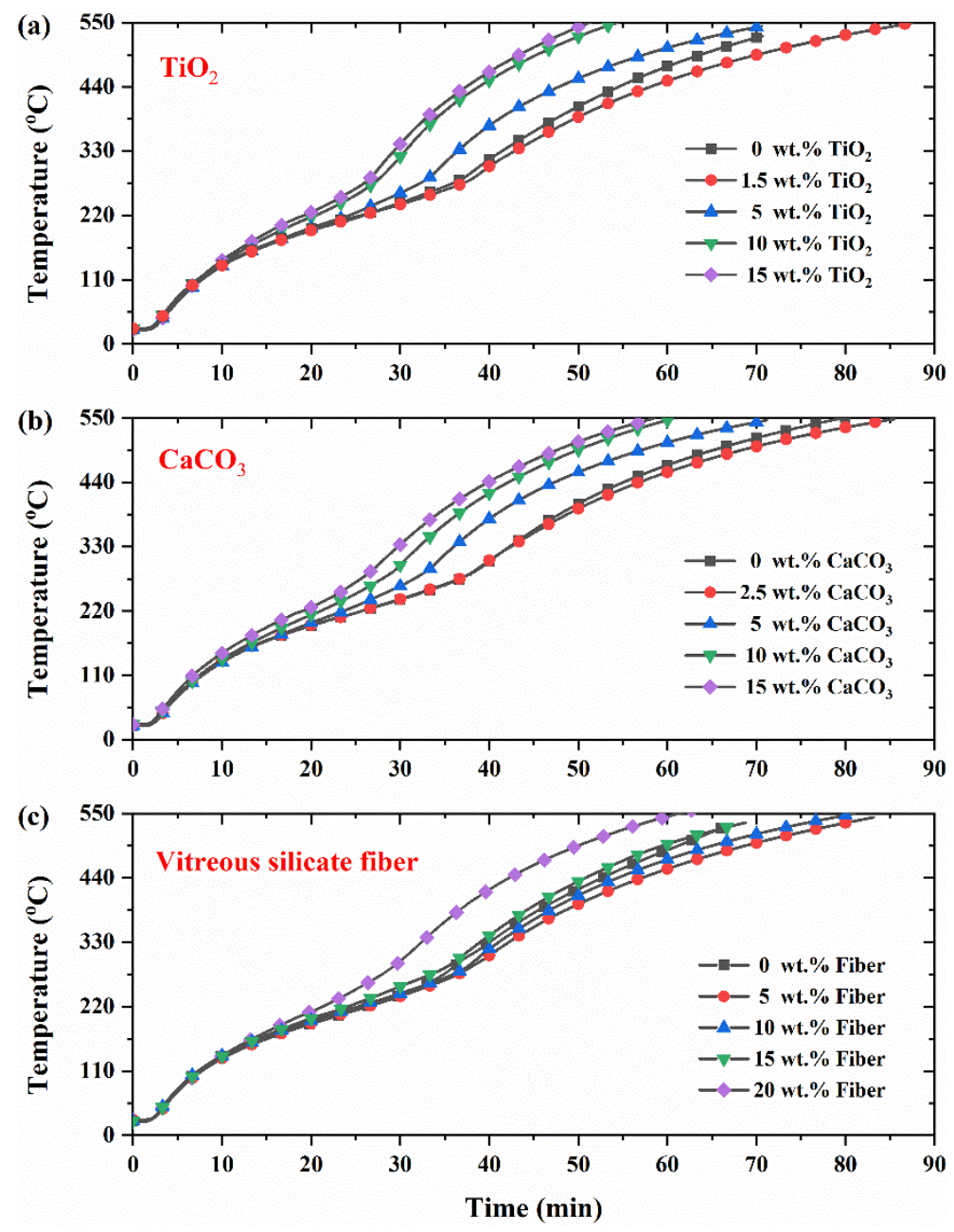

Figure 9 Fire-resistance performance of ZB-free intumescent coatings with different levels of $\mathrm{TiO}_{2}$, $\mathrm{CaCO}_{3}$, and vitreous silicate fiber.

The exposure times of the steel plates to reach the critical temperatures are given in Figure 10. By adjusting the mass fraction of $\mathrm{TiO}_{2}$ from 0 to $15 \mathrm{wt} . \%$ in the formulations, the critical times of the steel plates to 400 and $550^{\circ} \mathrm{C}$ were first increased and then gradually decreased. The best performance was found with the coating containing $1.5 \mathrm{wt} . \% \mathrm{TiO}_{2}$ (T1.5) for which the steel plates stood 51.6 and 87.7 min before reaching the critical temperatures of 400 and $550{ }^{\circ} \mathrm{C}$, respectively. A similar trend was found in the $\mathrm{ZB}$-free intumescent coatings with different levels of $\mathrm{CaCO}_{3}$ and the fiber. Among the investigated formulations, the optimal mass fraction of $\mathrm{CaCO}_{3}$ and the fiber are 2.5 and 5 wt.\%, respectively. The corresponding critical times to 400 and $550{ }^{\circ} \mathrm{C}$ are 50.7 and $86.3 \mathrm{~min}$ for the coating with 2.5 wt. $\% \mathrm{CaCO}_{3}(\mathrm{C} 2.5)$ and 50.7 and $85.1 \mathrm{~min}$ for the coating with 5 wt.\% vitreous silicate fiber (F5). Nevertheless, it is noted that significant uncertainties in some cases with long critical times were found, for example, the one without $\mathrm{TiO}_{2}(\mathrm{~T} 0)$ and the majority of the coatings in the case of the fiber. These uncertainties are the reason that some of the curves in Figure 9 were halted before $550{ }^{\circ} \mathrm{C}$. 


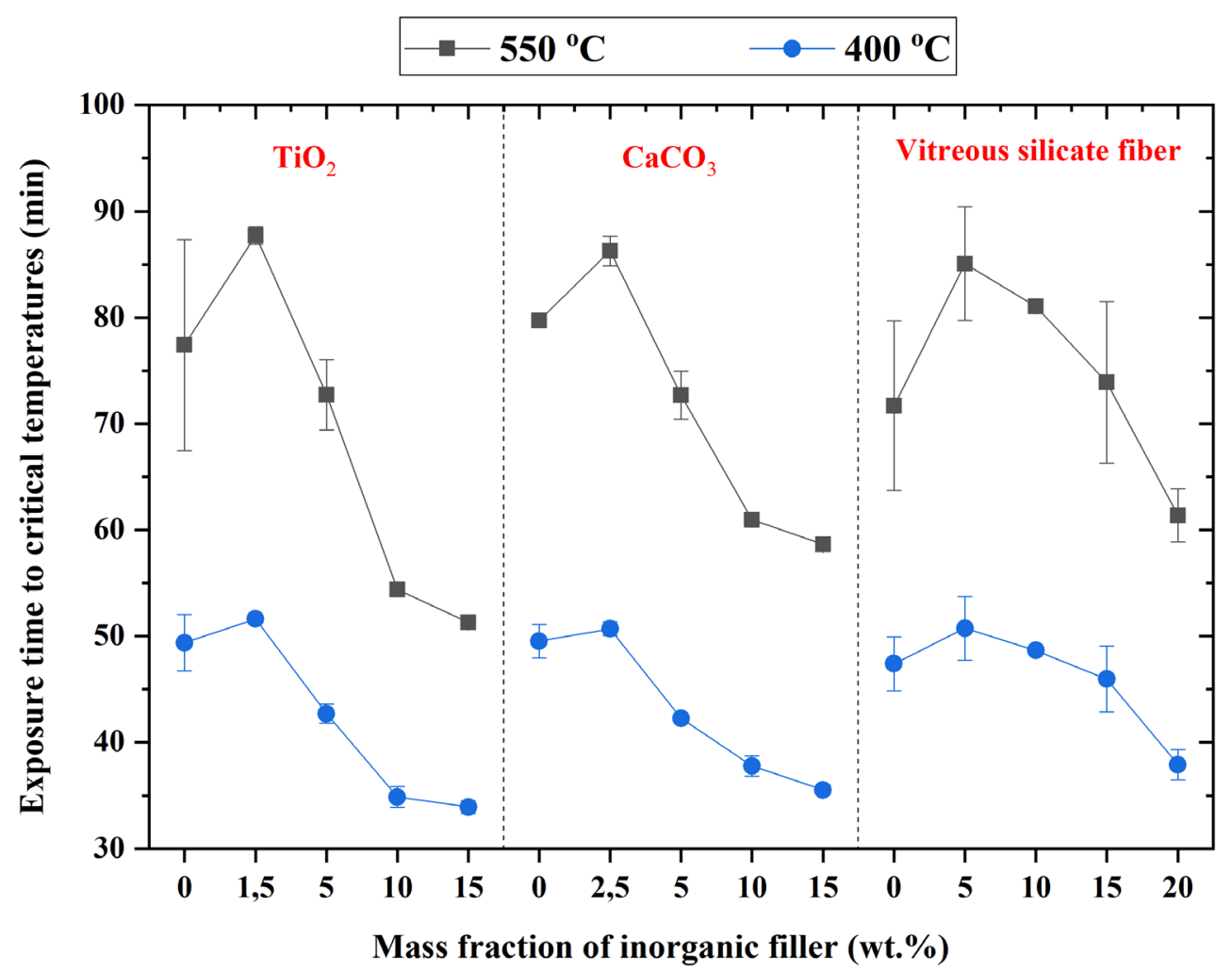

Figure 10 Critical times of ZB-free intumescent coatings with different levels of $\mathrm{TiO}_{2}, \mathrm{CaCO}_{3}$, and vitreous silicate fiber.

\subsubsection{Physical appearance of the intumescent chars}

The effects of $\mathrm{TiO}_{2}, \mathrm{CaCO}_{3}$, and vitreous silicate fiber on the physical appearance of the intumescent chars were further examined. Figure 11 shows the relative expansion of the chars produced from the ZB-free intumescent coatings. By increasing the content of $\mathrm{TiO}_{2}$ or $\mathrm{CaCO}_{3}$ in the $\mathrm{ZB}$-free formulations, the relative expansion of the chars was gradually decreased. This trend is in accordance with the variation of the critical times shown in Figure 10, except for the coatings without $\mathrm{TiO}_{2}$ or $\mathrm{CaCO}_{3}$. With respect to the fiber, the relative expansion of the chars was first boosted and then reduced. This coincides with the effects of the fiber on the critical times of the coated steel plates. The char with the highest relative expansion (F5) was produced from the coating that obtained the longest critical times among the formulations with different levels of the fiber. 


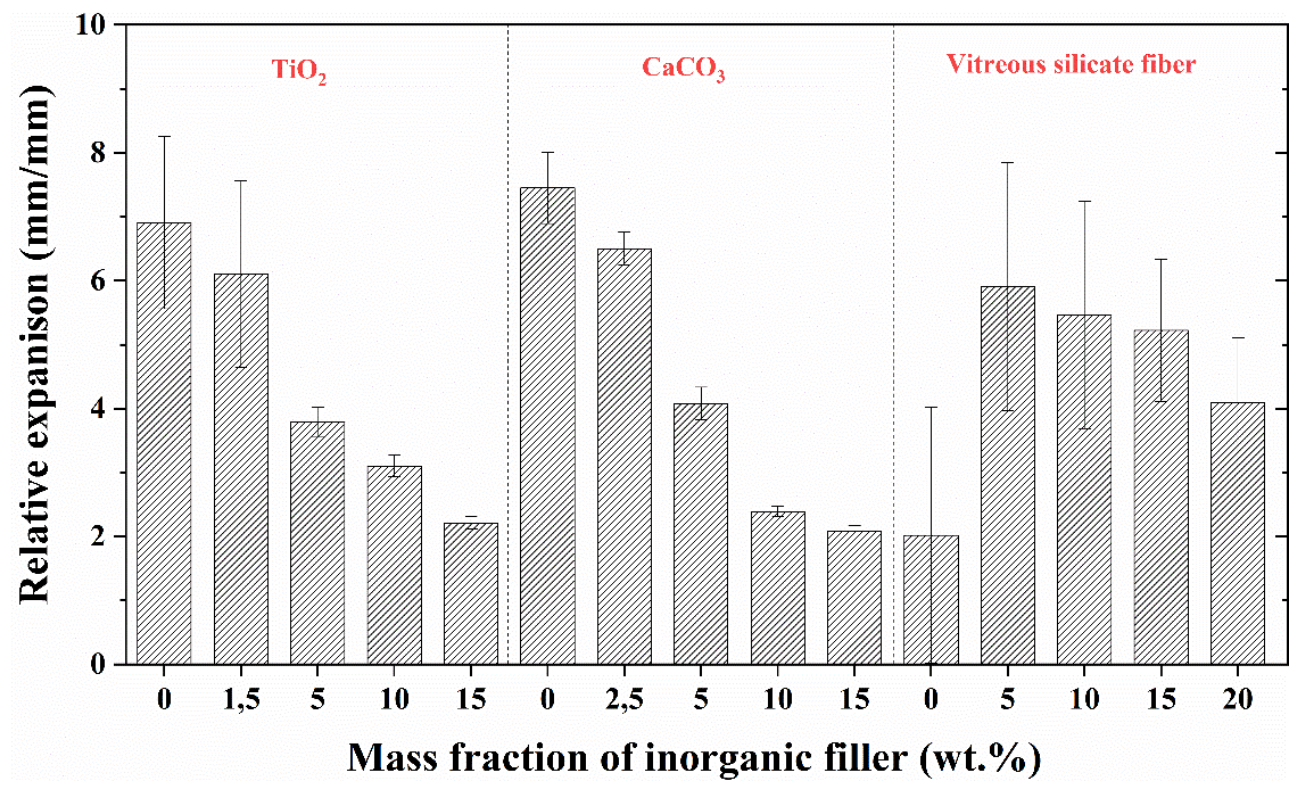

Figure 11 Char expansions relative to the initial coating thickness as a function of the levels of $\mathrm{TiO}_{2}$, $\mathrm{CaCO}_{3}$, and vitreous silicate fiber in the ZB-free intumescent coatings. Error bars represent the standard deviation.

The uncertainties on the relative expansion of the chars are rather noteworthy, especially for the coatings with 0 and $1.5 \mathrm{wt} . \% \mathrm{TiO}_{2}$ and the coatings with different levels of vitreous silicate fiber. In all these cases, the top layers of the chars completely detached and actually fell off, disintegrating into smaller pieces. The occurrence or degree of detachment was not repeatable in the furnace experiments, and therefore a large uncertainty exists in the assessment of the expansion factor of these chars. The detachment of a char top layer could happen during the fire-resistance experiments, during the period of cooling down of the furnace, or during the process of removing the char from the furnace door. However, the latter two options only influence the measurement of the char expansion, while the former has a significant impact on the temperature response of the steel plate, (i.e. the fireresistance performance of the coating). Therefore, the detachment during the fire-resistance experiments probably resulted in the large deviations seen for the critical times (e.g. T0 and F0 in Figure 10). In particular, the formulation with $0 \mathrm{wt} . \%$ vitreous silicate fiber had a relative expansion varied from $3.4 \mathrm{~mm} / \mathrm{mm}$ down to nearly zero, corresponding to the case where the coating burnt out during the experiment, leaving a large and continuous cavity through the few persistent char residues. For this case, plenty of fragments of the char was found on the bottom of the furnace.

As it has been mentioned in the case of the ZB-containing intumescent coatings, char expansion would also relate to the epoxy binder content that was accordingly decreased with raising the levels of the target components. Therefore, to confirm the effects of $\mathrm{TiO}_{2}, \mathrm{CaCO}_{3}$, and the fiber, it is necessary to discuss the role of the binder system in the relative expansion of the ZB-free intumescent 
coatings. Figure 12 shows the relationship between the relative expansion and the content of the binder system in the coatings. It can be seen that the binder content seems to demonstrate some connections with the char expansion, however, the extent to which the relative expansion was affected clearly depends on the investigated inorganic components, i.e. $\mathrm{TiO}_{2}, \mathrm{CaCO}_{3}$, and vitreous silicate fiber.

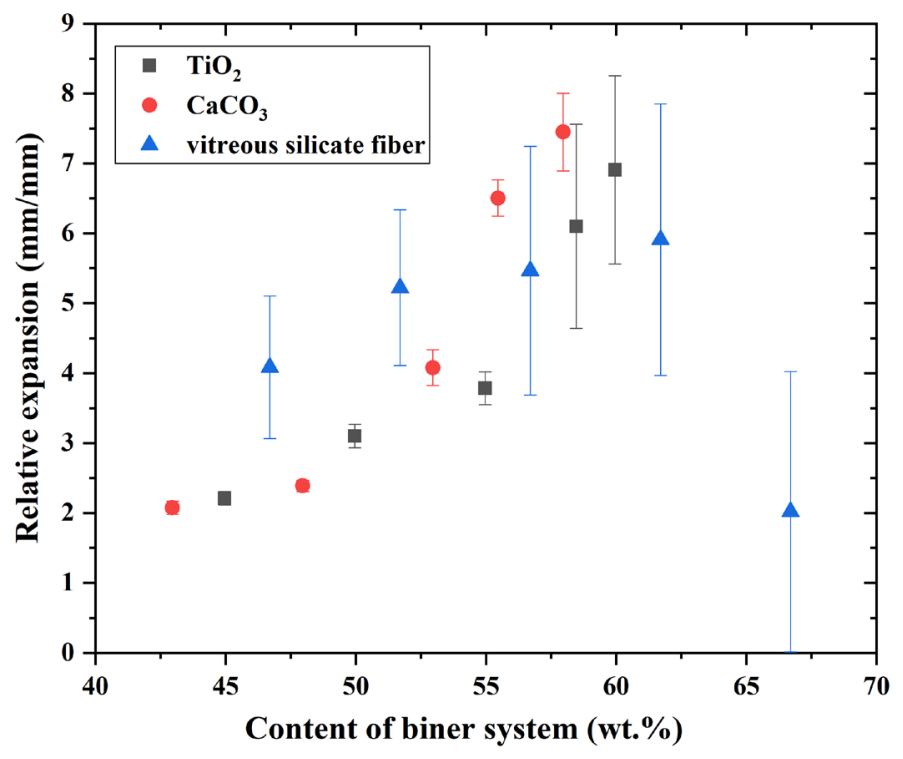

Figure 12 Relative expansion of the intumescent chars as a function of the content of the binder system (including the epoxy resin, diluent, amide, and catalyst).

The cross-sections of the chars were investigated after cutting with a scalpel and the results are shown in Figure $13\left(\mathrm{TiO}_{2}\right)$, Figure $14\left(\mathrm{CaCO}_{3}\right)$, and Figure 15 (vitreous silicate fiber). In this case, the photos were taken with a digital camera (as opposed to the digital microscope), as most of these chars were too fragile to hold themselves together while placed horizontally on the stage of the digital microscope. $\mathrm{TiO}_{2}$ and $\mathrm{CaCO}_{3}$ bear a strong resemblance in how they affect the morphology of the chars. This is in good agreement with their effects on the critical times and relative expansion. A sponge-like phase, characterized with a light-yellow color (outcome of severe oxidation of char layers $[29,30])$, with a thin compact layer underneath was found in the formulation without $\mathrm{TiO}_{2}$ or $\mathrm{CaCO}_{3}$ (see Figure 13 and Figure 14). It is hard to maintain the integrity of the sponge-like phase and it detached to different degrees either during the fire-resistance experiments and cooling down of the furnace (e.g. the case with $0 \mathrm{wt} . \% \mathrm{TiO}_{2}$ ) or while the char was being transferred out from the furnace (e.g. the case with 0 wt.\% $\mathrm{CaCO}_{3}$ ). By increasing the contents of $\mathrm{TiO}_{2}$ and $\mathrm{CaCO}_{3}$ in the coatings, the sponge-like phase was gradually transformed into a less expanded and oxidized macroporous phase. 

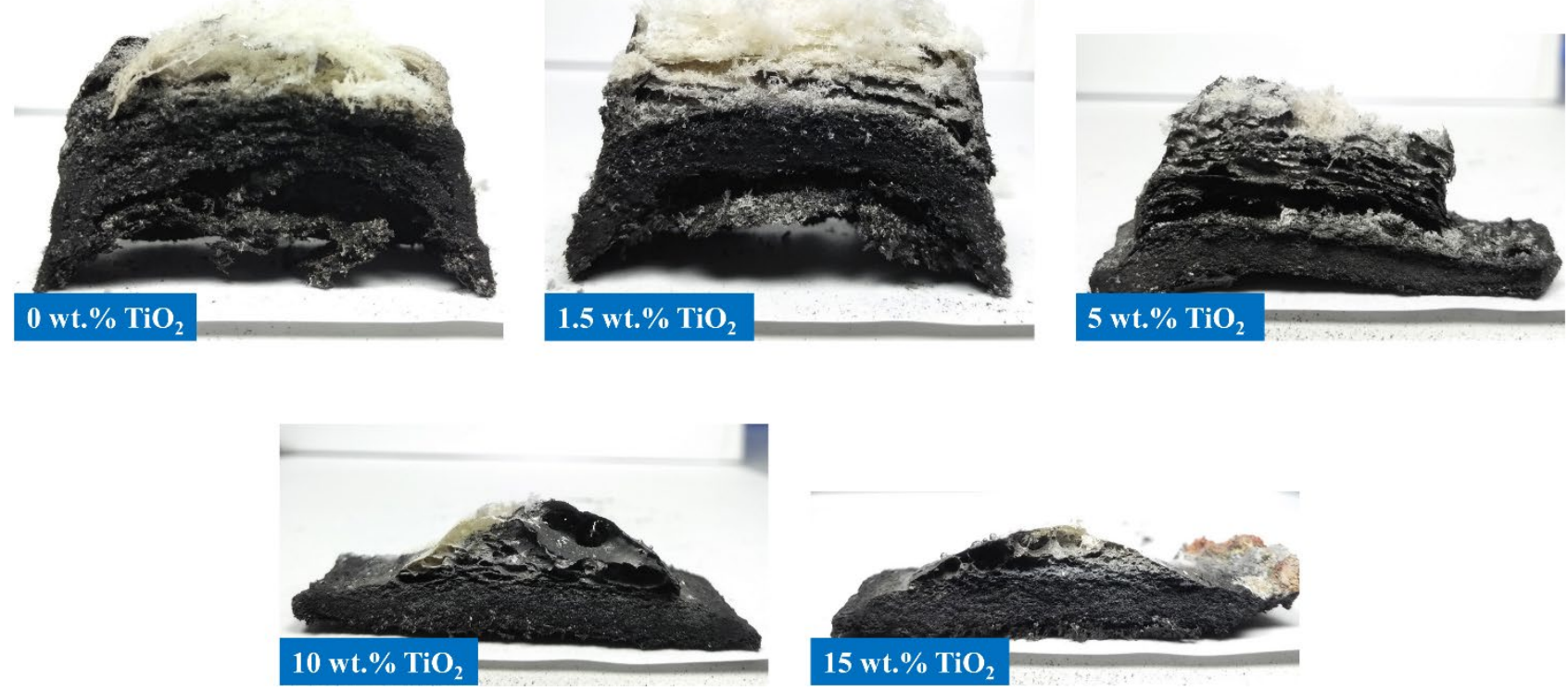

Figure 13 Cross-sections of the chars produced with the ZB-free intumescent coatings with different levels of $\mathrm{TiO}_{2}$. The top layers in the case of $0 \mathrm{wt} . \% \mathrm{TiO}_{2}$ were partially detached.
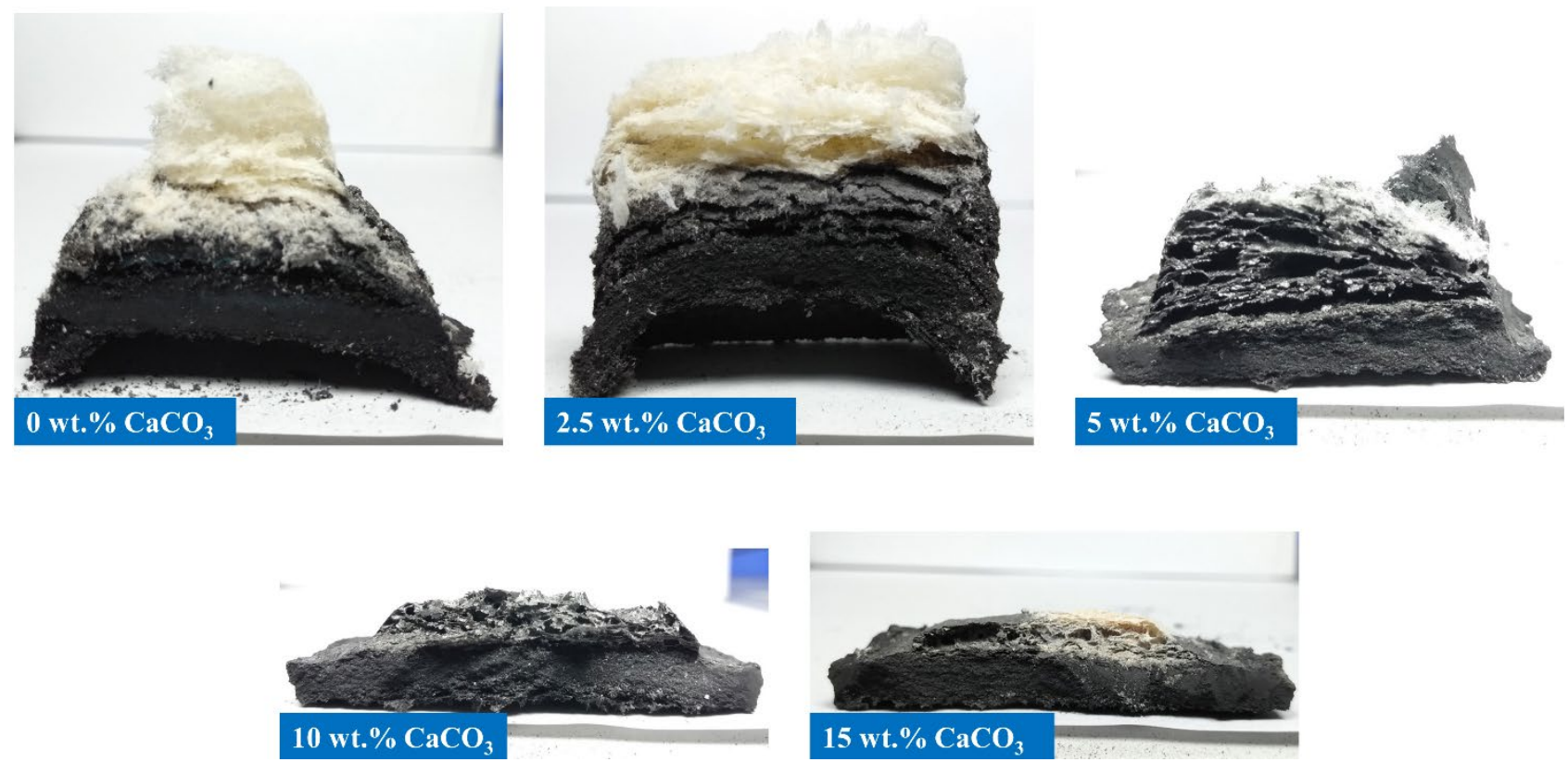

Figure 14 Cross-sections of the chars produced with the ZB-free intumescent coatings with different levels of $\mathrm{CaCO}_{3}$.

The improved morphological structures of the chars are probably on account of the interactions between the APP and $\mathrm{TiO}_{2}$ or $\mathrm{CaCO}_{3}$. Phosphoric groups of APP and its derivatives can react with $\mathrm{TiO}_{2}$ and $\mathrm{CaCO}_{3}$, forming titanium phosphate (e.g. $\mathrm{TiP}_{2} \mathrm{O}_{7}$ ) and calcium phosphate (e.g. $\left.\mathrm{Ca}\left(\mathrm{PO}_{3}\right)_{2}\right)$, respectively [37,42]. The formation of these phosphates can influence the chemical (e.g. anti- 
oxidation) and physical (e.g. morphological structure and emissivity of the surface) properties of intumescent chars [7,10,13]. Mariappan et al. investigated the effects of $\mathrm{TiO}_{2}$ on the fire-resistance performance of cellulosic intumescent coatings according to standard cellulosic fire test curve (ISO834), and found that the ratio of APP to $\mathrm{TiO}_{2}$ near to their stoichiometric reaction ratio (2 $\mathrm{mol} / \mathrm{mol}$ ) could benefit the performance of the intumescent coatings most [13]. Excess amount of $\mathrm{TiO}_{2}$ was suspected to affect the char structure and inhibit the expansion of chars $[10,13]$. Considering that the reaction between $\mathrm{CaCO}_{3}$ and APP is quite similar to the case of $\mathrm{TiO}_{2}$, an optimal ratio for the stoichiometry between $\mathrm{CaCO}_{3}$ and APP may also exist and influence the performance of the intumescent coatings. For the present study, the most prominent improvement on the char structures (disappearance of the oxidized sponge-like phase) arose when the content of $\mathrm{TiO}_{2}$ or $\mathrm{CaCO}_{3}$ was 5 wt.\%. In these two coatings, the ratios of APP to the total amount of $\mathrm{TiO}_{2}$ and $\mathrm{CaCO}_{3}($ see compositions in Table 2) are $1.8 \mathrm{~mol} / \mathrm{mol}$ (C5) and $2.1 \mathrm{~mol} / \mathrm{mol}$ (T5), which are quite close to the theoretical stoichiometric value $(2 \mathrm{~mol} / \mathrm{mol})$.

With respect to the vitreous silicate fiber, its influence on the morphology of the chars is moderately different from that of $\mathrm{TiO}_{2}$ and $\mathrm{CaCO}_{3}$. As shown in Figure 15, the primary structures of the chars (i.e. a sponge-like phase at the top and a compact phase at the bottom) did not change even when the level of the fiber was increased to $20 \mathrm{wt} . \%$. However, the char structure including the sponge-like and compact phase became denser with the content of the fiber increasing. Unlike the cases of $\mathrm{TiO}_{2}$ and $\mathrm{CaCO}_{3}$, the reactions of the vitreous silicate fiber (or similar to this type) with other active ingredients in the intumescent coating formulations (e.g. APP) have barely been reported in the relevant literature [10,43-46]. Duquesne et al. studied the effects of mineral fiber on the fire protection of intumescent coatings with an epiradiator, and claimed that the fibers were modified in their crystallinity or reacted with components (such as APP or its degradation products) during the heat treatment [10]. However, in our earlier work, we only observed the crystalline phase of $\mathrm{AlPO}_{4}$ in the top and middle layers of the char produced from an intumescent coating without zinc borate [30]. The shape of the fiber was maintained in the char layers regardless of the formation of $\mathrm{AlPO}_{4}$. It suggests that the reactivity of this fiber is quite limited and only the very surface of the fiber can react with derivatives of APP at high temperatures. In fact, the rod-shaped fiber was more likely to play a role of physically reinforcing the network to keep the char integrity [44,47]. Thus, without the support of the fiber (i.e. the coating with $0 \mathrm{wt} . \%$ fiber), the char was observed to be severely burnt, leaving penetrated cavities in the residual char and plenty of scattered pieces on the furnace chamber floor. 

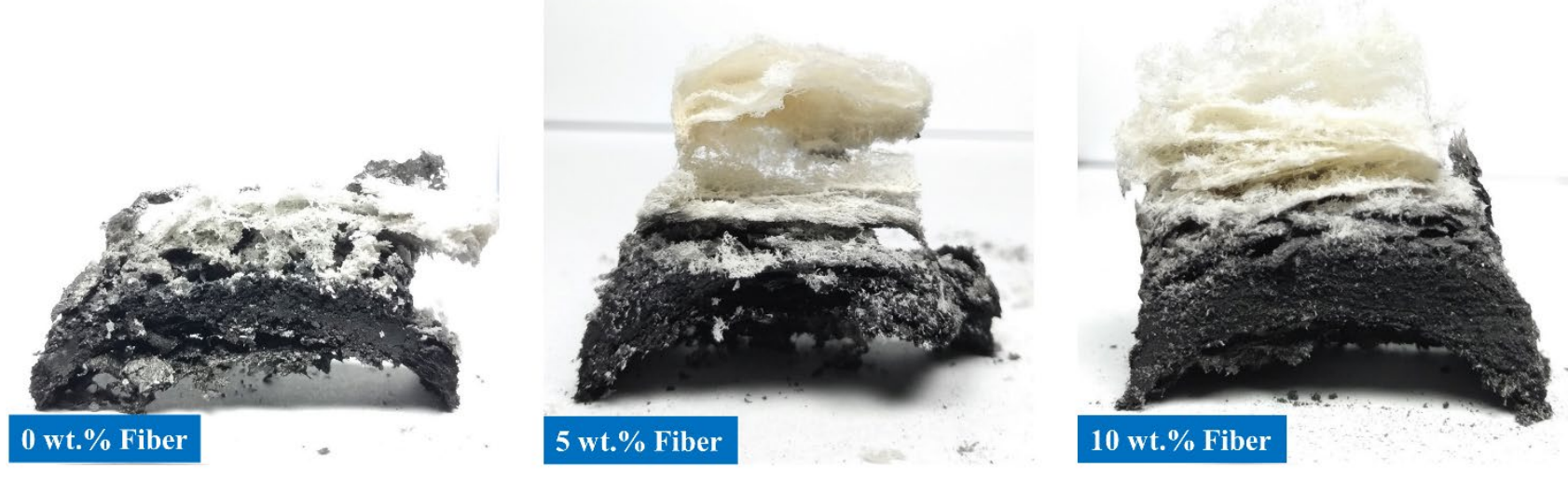

10 wt. \% Fiber

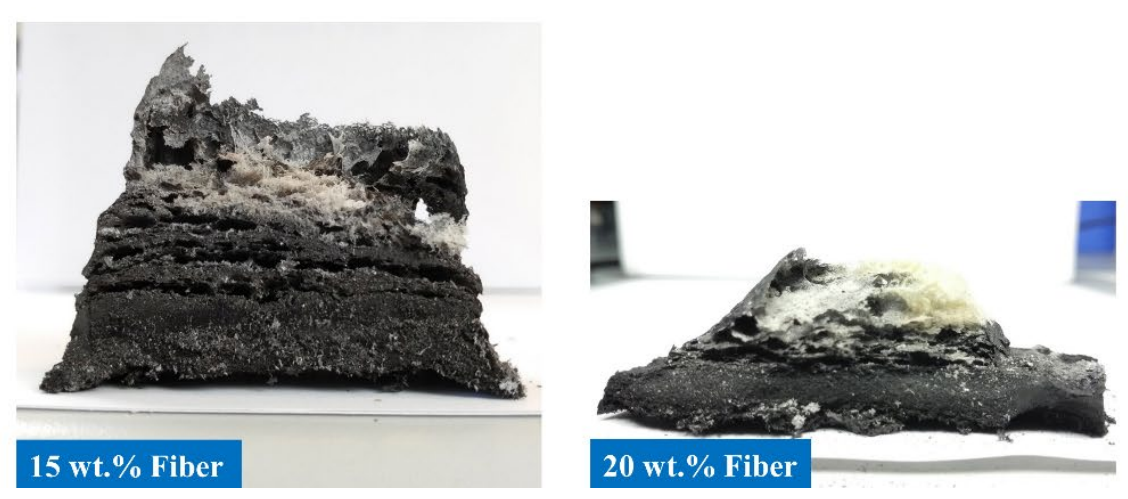

Figure 15 Cross-sections of the chars produced with the ZB-free intumescent coatings with different levels of vitreous silicate fiber.

The effects of $\mathrm{TiO}_{2}, \mathrm{CaCO}_{3}$, and vitreous silicate fiber on the physical appearance of the chars explains the temperature response of the coated steel plates observed in the fire-resistance experiments. The cases with the low content of $\mathrm{TiO}_{2}, \mathrm{CaCO}_{3}$, or vitreous silicate fiber resulted in the high relative expansion of the chars, which therefore gave more protection (long critical times) to the underlying steel plate. However, these high-swelled chars were mainly contributed by the spongelike layers that are prone to detach from the bulk of the char (e.g. T0 and C0). Increasing the level of $\mathrm{TiO}_{2}, \mathrm{CaCO}_{3}$, or the fiber clearly improved morphological structures of the chars and reduced the probability of detachment. Therefore, the longest critical times to 400 and $550{ }^{\circ} \mathrm{C}$ were seen when the char exhibited high expansion and maintained its integrity (i.e. T1.5, C2.5, and F5). Nevertheless, it is hard to generalize the respective best performance found with the coatings T1.5, C2.5, and F5 to cases of industrial hydrocarbon fire tests. Compared with the static-electrical heating applied in the present fire-resistance experiments, the turbulent flow exposed by the intumescent coating samples evaluated in industrial hydrocarbon fire tests is more vigorous [28]. The sponge-like phases of T1.5, $\mathrm{C} 2.5$, and F5 that were barely intact in the present case may be completely damaged in the industrial fire tests, leading to inferior fire-resistance performance. Therefore, the char structures that were 
improved with a high content of $\mathrm{TiO}_{2}, \mathrm{CaCO}_{3}$, or the fiber, e.g. T5, C5, and F10, are probably more practically viable from the perspective of the application of ZB-free intumescent coatings in real hydrocarbon fire scenarios.

\section{Conclusions}

The effects of ammonium polyphosphate (APP), melamine (MEL), $\mathrm{TiO}_{2}, \mathrm{CaCO}_{3}$, and vitreous silicate fiber on the performance of selected ZB-containing and ZB-free intumescent coatings were investigated, using the fire-resistance experiments carried out with the temperature-time curve defined in the standard UL1709. Increasing the content of APP or decreasing the content of MEL generally benefited the performance of the ZB-containing intumescent coatings, in the aspects of critical times to 400 and $550{ }^{\circ} \mathrm{C}$ and physical appearance of the char (including relative expansion and formation of macroporous and compact structures). Among the investigated formulations, the best performance was found with the coating containing $25 \mathrm{wt} . \%$ APP or $5 \mathrm{wt}$ \% MEL. The positive effect of raising the APP level was owing to the promoted interactions of APP with the epoxy binder and zinc borate, while the inferior performance of the coatings by increasing the content of MEL was related to the negative influence from the changes on the binder system. Varying the levels of $\mathrm{TiO}_{2}$, $\mathrm{CaCO}_{3}$, and the fiber barely had an influence on the performance of the ZB-containing coatings. The presence of zinc borate significantly constricted the room for these inorganic fillers to play a role. Therefore, reducing the amount of $\mathrm{TiO}_{2}, \mathrm{CaCO}_{3}$, or the fiber and allowing high contents of active ingredients (e.g. APP, zinc borate), may lead to better coating performance of the ZB-containing formulations.

More prominent effects of $\mathrm{TiO}_{2}, \mathrm{CaCO}_{3}$, and the fiber were observed on the performance of $\mathrm{ZB}$-free intumescent coatings. The coating with 1.5 wt.\% $\mathrm{TiO}_{2}, 2.5$ wt. $\% \mathrm{CaCO}_{3}$, or 5 wt.\% vitreous silicate fiber was found with the longest critical time to both 400 and $550{ }^{\circ} \mathrm{C}$, among the investigation regarding $\mathrm{TiO}_{2}, \mathrm{CaCO}_{3}$, and the fiber, respectively. A high content of $\mathrm{TiO}_{2}$ or $\mathrm{CaCO}_{3}$, inhibited the char expansion of the ZB-free intumescent coatings, but also improved the char phases from a spongelike - compact structure, vulnerable to detachment, to a macroporous - compact structure that is more mechanically stable against turbulent hydrocarbon fires. With respect to the vitreous silicate fiber, it mainly physically reinforced the internal network of the intumescent chars, and thereby affected their morphological structures.

\section{Acknowledgments}

Financial support from the Hempel Foundation to CoaST (The Hempel Foundation Coatings Science and Technology Centre) is gratefully acknowledged. 


\section{Declarations of interest}

None.

\section{Data availability}

The raw and processed data required to reproduce these findings are available to download from [https://data.mendeley.com/datasets/j6436wxxb9/draft?a=a73c42d9-1c01-42a9-9542-cac7ea25c7ac].

\section{Reference}

[1] C. Zhang, Reliability of Steel Columns Protected by Intumescent Coatings Subjected to Natural Fires, Springer Berlin Heidelberg, Berlin, Heidelberg, 2015.

[2] EN 1991-1-2, Eurocode 1: Actions on structures -Part 1-5: General actions - Actions on structures exposed to fire, European Committee for Standardization, 2002.

[3] T. Mariappan, Recent developments of intumescent fire protection coatings for structural steel: A review, J. Fire Sci. 34 (2016) 120-163.

[4] M. Jimenez, S. Duquesne, S. Bourbigot, High-Throughput Fire Testing for Intumescent Coatings, Ind. Eng. Chem. Res. 45 (2006) 7475-7481.

[5] M.C. Yew, N.H. Ramli Sulong, M.K. Yew, M.A. Amalina, M.R. Johan, Influences of flameretardant fillers on fire protection and mechanical properties of intumescent coatings, Prog. Org. Coatings. 78 (2015) 59-66.

[6] M. Morys, B. Illerhaus, H. Sturm, B. Schartel, Size is not all that matters: Residue thickness and protection performance of intumescent coatings made from different binders, J. Fire Sci. 35 (2017) 284-302.

[7] J. Alongi, Z. Han, S. Bourbigot, Intumescence: Tradition versus novelty. A comprehensive review, Prog. Polym. Sci. 51 (2015) 28-73.

[8] Q.F. Gillani, F. Ahmad, M.I.A. Mutalib, P.S. Melor, S. Ullah, A. Arogundade, Effect of Dolomite Clay on Thermal Performance and Char Morphology of Expandable Graphite Based Intumescent Fire Retardant Coatings, Procedia Eng. 148 (2016) 146-150.

[9] H. Aziz, F. Ahmad, Effects from nano-titanium oxide on the thermal resistance of an intumescent fire retardant coating for structural applications, Prog. Org. Coatings. 101 (2016) 431-439. 
[10] S. Duquesne, P. Bachelet, S. Bellayer, S. Bourbigot, W. Mertens, Influence of inorganic fillers on the fire protection of intumescent coatings, J. Fire Sci. 31 (2013) 258-275.

[11] H. Aziz, F. Ahmad, M. Zia-ul-Mustafa, Effect of Titanium Oxide on Fire Performance of Intumescent Fire Retardant Coating, Adv. Mater. Res. 935 (2014) 224-228.

[12] N. Amir, F. Ahmad, M.H.A. Halim, Q.F. Gillani, P.S.M. Megat Yusoff, H. Aziz, R. Ahmad, Synergistic Effects of Titanium Dioxide and Zinc Borate on Thermal Degradation and Water Resistance of Epoxy Based Intumescent Fire Retardant Coatings, Key Eng. Mater. 740 (2017) $41-47$.

[13] T. Mariappan, A. Agarwal, S. Ray, Influence of titanium dioxide on the thermal insulation of waterborne intumescent fire protective paints to structural steel, Prog. Org. Coatings. 111 (2017) 67-74.

[14] S. Ullah, F. Ahmad, A.M. Shariff, M.A. Bustam, G. Gonfa, Q.F. Gillani, Effects of ammonium polyphosphate and boric acid on the thermal degradation of an intumescent fire retardant coating, Prog. Org. Coatings. 109 (2017) 70-82.

[15] S. Ullah, F. Ahmad, P.S.M.M. Yusoff, Effect of boric acid and melamine on the intumescent fire-retardant coating composition for the fire protection of structural steel substrates, J. Appl. Polym. Sci. 128 (2013) 2983-2993.

[16] S. Ullah, F. Ahmad, P.S.M. Megat-Yuso, Effect of Boric Acid with Kaolin Clay on Thermal Degradation of Intumescent Fire Retardant Coating, J. Appl. Sci. 11 (2011) 3645-3649.

[17] S. Ullah, F. Ahmad, A.M. Shariff, M.A. Bustam, Synergistic effects of kaolin clay on intumescent fire retardant coating composition for fire protection of structural steel substrate, Polym. Degrad. Stab. 110 (2014) 91-103.

[18] M. Zia-ul-Mustafa, F. Ahmad, S. Ullah, N. Amir, Q.F. Gillani, Thermal and pyrolysis analysis of minerals reinforced intumescent fire retardant coating, Prog. Org. Coatings. 102 (2017) 201-216.

[19] J. Wang, G. Wang, Influences of montmorillonite on fire protection, water and corrosion resistance of waterborne intumescent fire retardant coating for steel structure, Surf. Coatings Technol. 239 (2014) 177-184.

[20] B. Bodzay, K. Bocz, Z. Bárkai, G. Marosi, Influence of rheological additives on char formation and fire resistance of intumescent coatings, Polym. Degrad. Stab. 96 (2011) 355-362. 
[21] W.A. Wan Zaharu, B. Ariwahjoed, P. Hussain, Effect of Vermiculite Addition on Thermal Characteristic of Water-based Acrylic Fire Retardant Coating Formulation, J. Appl. Sci. 11 (2011) 1763-1769.

[22] B. Gardelle, S. Duquesne, P. Vandereecken, S. Bellayer, S. Bourbigot, Resistance to fire of intumescent silicone based coating: The role of organoclay, Prog. Org. Coatings. 76 (2013) $1633-1641$.

[23] A. Lucherini, N. Abusamha, J. Segall-Brown, C. Maluk, Experimental study on the onset of swelling for thin intumescent coatings, J. Phys. Conf. Ser. 1107 (2018) 032017-1-032017-6.

[24] M. Morys, B. Illerhaus, H. Sturm, B. Schartel, Revealing the inner secrets of intumescence: Advanced standard time temperature oven (STT Mufu + )- $\mu$-computed tomography approach, Fire Mater. 41 (2017) 927-939.

[25] A. Lucherini, C. Maluk, Assessing the onset of swelling for thin intumescent coatings under a range of heating conditions, Fire Saf. J. 106 (2019) 1-12.

[26] M. Bartholmai, B. Schartel, Assessing the performance of intumescent coatings using benchscaled cone calorimeter and finite difference simulations, Fire Mater. 31 (2007) 187-205.

[27] M. Bartholmai, R. Schriever, B. Schartel, Influence of external heat flux and coating thickness on the thermal insulation properties of two different intumescent coatings using cone calorimeter and numerical analysis, Fire Mater. 27 (2003) 151-162.

[28] Y. Zeng, C.E. Weinell, K. Dam-Johansen, L. Ring, S. Kiil, Comparison of an industrial- and a laboratory-scale furnace for analysis of hydrocarbon intumescent coating performance, accepted by Journal of Fire Sciences on $8^{\text {th }}$ January 2020.

[29] L. Wang, B. Chen, C. Zhang, G. Li, Experimental study on insulative properties of intumescent coating exposed to standard and nonstandard furnace curves, Fire Mater. 43 (2019) 782-793.

[30] Y. Zeng, C.E. Weinell, K. Dam-Johansen, L. Ring, S. Kiil, Exposure of hydrocarbon intumescent coatings to the UL1709 heating curve and furnace rheology: Effects of zinc borate on char properties, Prog. Org. Coatings. 135 (2019) 321-330.

[31] M.C. Yew, N.H. Ramli Sulong, Effect of Epoxy Binder on Fire Protection and Bonding Strength of Intumescent Fire Protective Coatings for Steel, Adv. Mater. Res. 168-170 (2010) $1228-1232$.

[32] G. Wang, J. Yang, Influences of molecular weight of epoxy binder on fire protection of 
waterborne intumescent fire resistive coating, Surf. Coatings Technol. 206 (2012) 2146-2151.

[33] M. Gomez-Mares, A. Tugnoli, G. Landucci, F. Barontini, V. Cozzani, Behavior of intumescent epoxy resins in fireproofing applications, J. Anal. Appl. Pyrolysis. 97 (2012) 99-108.

[34] R.G. Puri, A.S. Khanna, Intumescent coatings: A review on recent progress, J. Coatings Technol. Res. 14 (2017) 1-20.

[35] D.M. Yebra, C.E. Weinell, Key issues in the formulation of marine antifouling paints, in: Adv. Mar. Antifouling Coatings Technol., Elsevier, 2009: pp. 308-333.

[36] F. Samyn, S. Bourbigot, S. Duquesne, R. Delobel, Effect of zinc borate on the thermal degradation of ammonium polyphosphate, Thermochim. Acta. 456 (2007) 134-144.

[37] K.P. Nørgaard, K. Dam-Johansen, P. Català, S. Kiil, Laboratory and gas-fired furnace performance tests of epoxy primers for intumescent coatings, Prog. Org. Coatings. 77 (2014) $1577-1584$.

[38] R. Riahipour, A. Alizadeh Sahraei, N. van de Werken, M. Tehrani, K. Abrinia, M. Baniassadi, Improving flame-retardant, thermal, and mechanical properties of an epoxy using halogen-free fillers, Sci. Eng. Compos. Mater. 25 (2018) 939-946.

[39] P. Kiliaris, C.D. Papaspyrides, Polymer/layered silicate (clay) nanocomposites: An overview of flame retardancy, Prog. Polym. Sci. 35 (2010) 902-958.

[40] F.-Q. Fan, Z.-B. Xia, Q. Li, Z. Li, Effects of inorganic fillers on the shear viscosity and fire retardant performance of waterborne intumescent coatings, Prog. Org. Coatings. 76 (2013) $844-851$.

[41] X. Zhang, Y. Wu, X. Chen, H. Wen, S. Xiao, Theoretical Study on Decomposition Mechanism of Insulating Epoxy Resin Cured by Anhydride, Polymers (Basel). 9 (2017) 1-9.

[42] S. Deodhar, K. Shanmuganathan, Q. Fan, C.A. Wilkie, M.C. Costache, N.A. Dembsey, P.K. Patra, Calcium carbonate and ammonium polyphosphate-based flame retardant composition for polypropylene, J. Appl. Polym. Sci. 120 (2011) 1866-1873.

[43] M. Yasir, F. Ahmad, P.S.M. Megat-Yusoff, S. Ullah, M. Jimenez, Quantifying the effects of basalt fibers on thermal degradation and fire performance of epoxy-based intumescent coating for fire protection of steel substrate, Prog. Org. Coatings. 132 (2019) 148-158.

[44] M. Morys, B. Illerhaus, H. Sturm, B. Schartel, Variation of Intumescent Coatings Revealing Different Modes of Action for Good Protection Performance, Fire Technol. 53 (2017) 1569- 
1587.

[45] N. Amir, W.M.S.W. Othman, F. Ahmad, Fire resistance properties of ceramic wool fiber reinforced intumescent coatings, AIP Conf. Proc. 1669 (2015) 020062-1-020062-6.

[46] G. Canosa, P. V Alfieri, C.A. Giudice, Hybrid Intumescent Coatings for Wood Protection against Fire Action, Ind. Eng. Chem. Res. 50 (2011) 11897-11905.

[47] N. Amir, A.A. Abd. Majid, F. Ahmad, Effects of Hybrid Fibre Reinforcement on Fire Resistance Performance and Char Morphology of Intumescent Coating, MATEC Web Conf. 38 (2016) 03001. 